Portland State University

PDXScholar

1982

\title{
Developing an attitude test to predict treatment outcome in depressed and anxious outpatients : an exploratory study
}

Kathryn Ainslie Paris

Portland State University

Follow this and additional works at: https://pdxscholar.library.pdx.edu/open_access_etds

Part of the Psychoanalysis and Psychotherapy Commons, and the Psychology Commons Let us know how access to this document benefits you.

\section{Recommended Citation}

Paris, Kathryn Ainslie, "Developing an attitude test to predict treatment outcome in depressed and anxious outpatients : an exploratory study" (1982). Dissertations and Theses. Paper 3356.

https://doi.org/10.15760/etd.5235

This Thesis is brought to you for free and open access. It has been accepted for inclusion in Dissertations and Theses by an authorized administrator of PDXScholar. Please contact us if we can make this document more accessible: pdxscholar@pdx.edu. 
AN ABSTRACT OF THE THESIS of Kathryn Ainslie Paris for the Master of Science in Psychology presented December, 1982.

Title: Developing an Attitude Test to Predict Treatment Outcome in Depressed and Anxious Outpatients: An Exploratory Study.

APPROVED BY MEMBERS OF THE THESIS COMMITTEE:

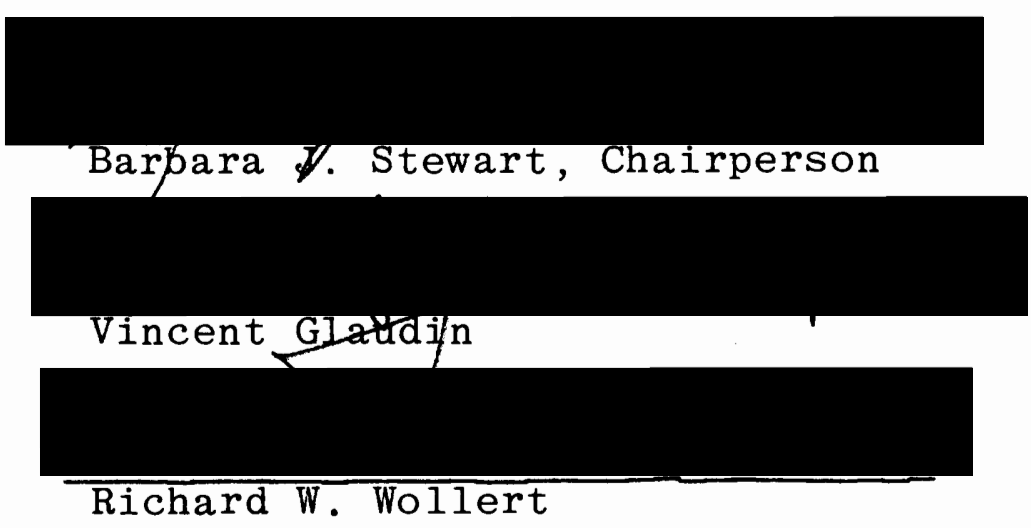

While much research has examined factors thought to affect patient compliance with therapeutic regimen, relatively little is known about the relationship between psychiatric patients' attitudes toward treatment regimen and their adherence to the treatment regimen. Compliance rates for psychiatric patients remain the lowest of the medical patient population, probably due to psychological and social characteristics of psychiatric patients. Because of a trend in the United States toward self-medication for an increasingly ambulatory psychiatric patient population, the ability to predict patient compliance with 
medication regimen has become more important than ever before. Before potential noncompliers can be identified and patient compliance predicted through the use of attitudes, an examination of the nature of these attitudes is needed. Scientific literature and theory suggest that attitude is one of several variables which corresponds to behavior. Specific attitudes are thought to develop as a result of real or vicarious experience with the attitude referent. In addition, research has shown that attitudes toward specific objects correlate highly with beliefs, behavioral intentions, and behavior. Therefore, it is hypothesized that psychiatric patients with prior medicine-taking experience will have developed different patterns of attitudes toward pharmacological treatment than will medicine-naive patients. The hypothesis implies that knowing these attitudes will permit prediction of compliance of experienced and naive patients with therapeutic regimen.

As the first step of investigating using attitudes to predict compliance, a 20-item Likert-type rating scale, the Psychiatric Medicine Attitude Scale (PMAS), was developed. An alternate forms reliability coefficient of .93 was obtained. Mean score for Form A for the psychiatric medicineexperienced subjects was 2.85 , for the medicine-naive subjects, 3.40. Form B scores were 3.17 for the experienced subjects and 3.51 for the naive subjects. These scores show that on both Forms $A$ and $B$, individuals without prior experience with psychiatric medicine tended to express more neg- 
ative attitudes toward the referent object than did the subjects who had previous medicine experience.

The next steps, outside the range of this project, will be to develop norms and to ascertain if compliance behaviors will be a function of PMAS scores. 
DEVELOPING AN ATTITUDE TEST TO PREDICT TREATMENT OUTCOME IN DEPRESSED AND ANXIOUS OUTPATIENTS:

AN EXPLORATORY STUDY

\author{
by \\ KATHRYN AINSLIE PARIS
}

A thesis submitted in partial fulfillment of the requirements for the degree of

\author{
MASTER OF SCIENCE \\ in \\ PSYCHOLOGY
}

Portland State University

1983 
TO THE OFFICE OF GRADUATE STUDIES AND RESEARCH:

The members of the Committee approve the thesis of Kathryn Ainslie Paris presented December, 1982.

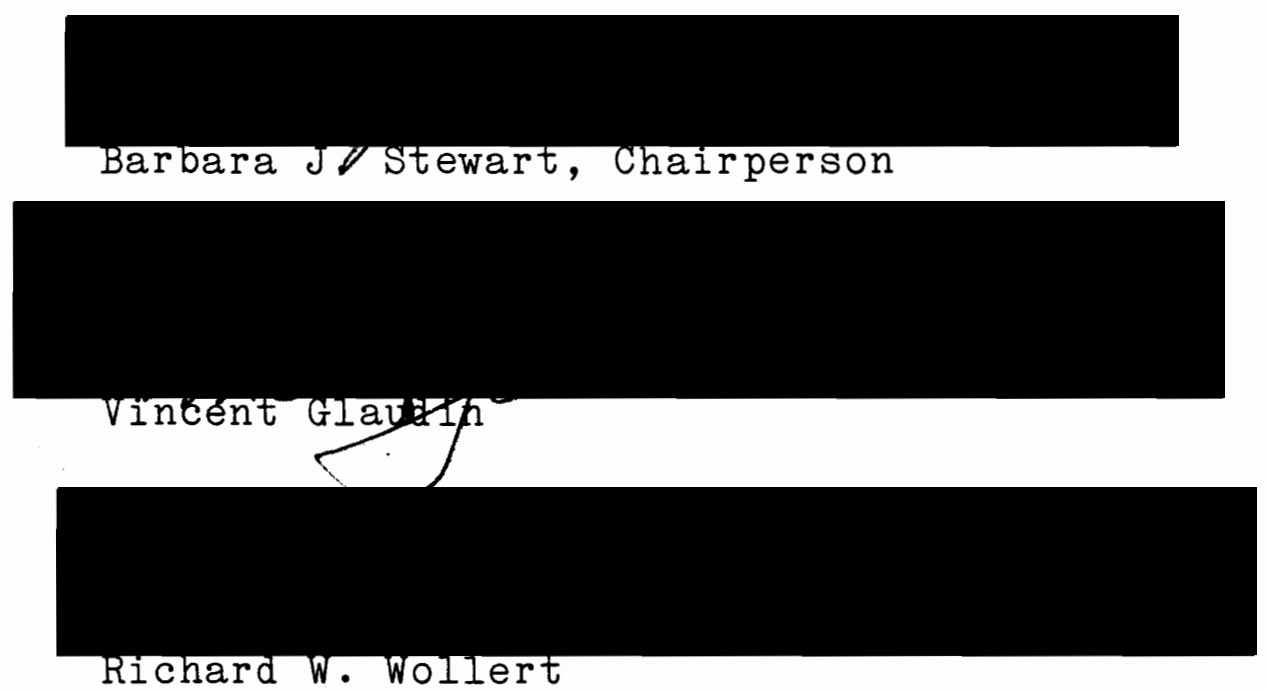

\section{APPROVED :}

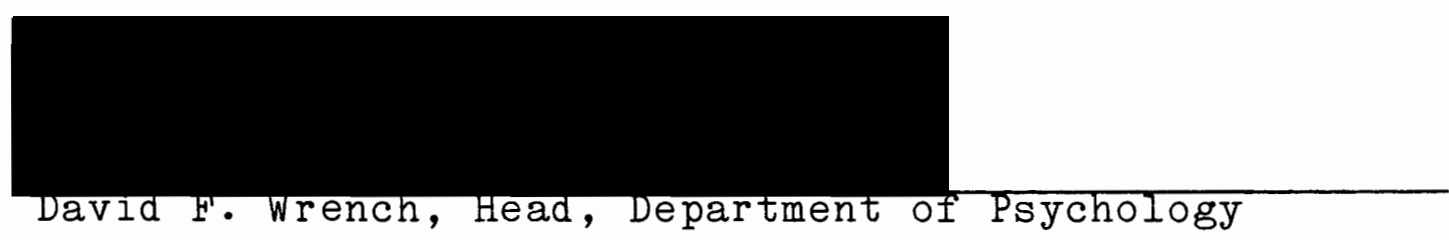

Stanley E. Rauch, Dean of Graduate Studies and Research 


\section{ACKNOWLEDGMENTS}

I am grateful for this opportunity to acknowledge the substantial contributions of my committee members, Drs. Barbara Stewart, Vincent Glaudin, and Richard Wollert, to this research. Each is a true educator who encouraged both my personal and academic growth during the thesis work.

As chairperson, Dr. Stewart's influence was significant. Very clearly, she provided the support which enabled the completion of the project. She also offered important critical evaluation and encouraged scientific curiosity at every stage of the work. She approached each task enthusiastically, making even the more obscure aspects of scientific examination manageable and interesting. I treasure her memos which included "some interesting notions about research" from Robert Pirsig's Zen and the Art of Motorcycle Maintenance. In addition to her academic support, Barbara's friendship was a lifeline during a turbulent period of my life. Besides modeling a successful and human, personal and professional style, she was available at school and at home whenever I needed her consultation. I am indebted to her and I miss her now.

To Dr. Glaudin goes credit for the very idea of the project. In addition, he directed and facilitated the research in such essential ways as providing bibliographic search 
support and supplying a clinical population. I benefited from both his remarkable command of scientific theory and his clinical acumen. Dr. Glaudin was also unusually accessible during the process and would encourage the smallest spurts of progress between regrettably long months of inertia. I would be very fortunate to work with an individual of his expertise and kindness again.

Although Dr. Wollert was invited to participate in the latter stages of the project, his comments and evaluation were always clear and useful. I appreciate his friendship as well. His participation rounded out the most caring and proficient thesis committee a graduate student will ever have. 
TABLE OF CONTENTS

PAGE

ACKNOWLEDGMENTS . . . . . . . . . . . . . . . . 11i

LIST OF LISTS . . . . . . . . . . . . . . . . . vii

LIST OF TABLES . . . . . . . . . . . . . . . . . vi1i

CHAPTER

I. INTRODUCTION . . . . . . . . . . . . . . . . . . I

Clinical History of Compliance . . . . . . . 2

Magnitude of Compliance and Noncompliance . . . 3

Determinants of Compliance . . . . . . . 4

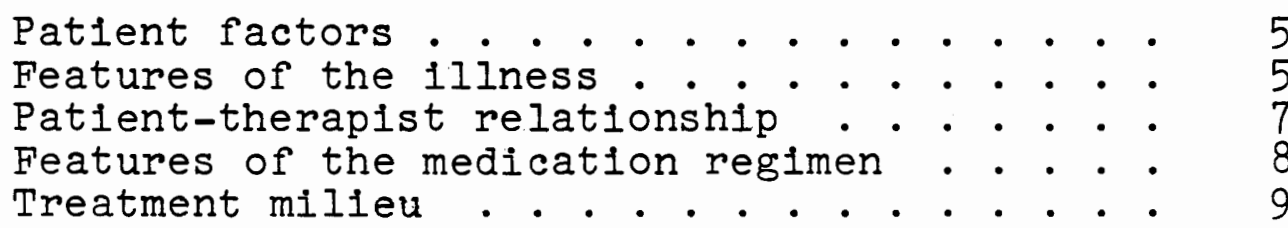

II. STATEMENT OF THE CLINICAL PROBLEM . . . . . . . . 10

Theoretical Foundations : . . . . . . . . . 13

Definitions of attitude . . . . . . . . . . 13

Attitude measurement using commitment-free

Personal and situational variables... . . 15

Attltudes and compliance . . . . . . . . 16

III. METHOD . . . . . . . . . . . . . 18

Part I-Scale Development . . . . . . . . 18

Subjects . . . . . . . . . . . . . 18

Instrument . . . . . . . . . . . . . . . . 18

Analysis and development of scale for Part II. 19

Part II-Scale Refinement . . . . . . . . 20 
CHAPTER

PAGE

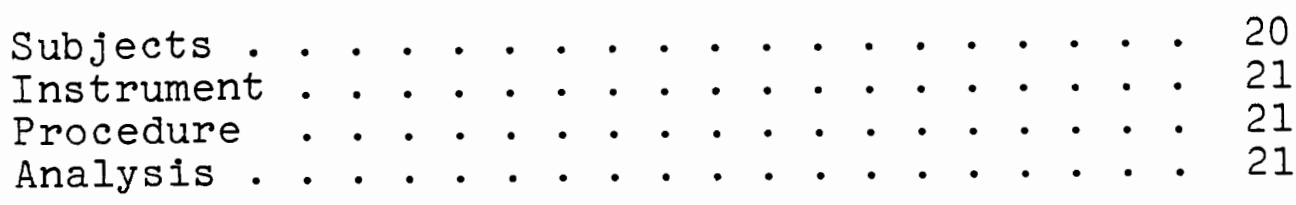

IV. RESULTS • • • • • • • • • • • • • • • • • • 23

Descriptive Data . . . . . . . . . . . . . . 23

Factor Analyses . • . • . . . . . . . . . 28

Alternate Form Construction (25-item PMAS) . . . 29

Scale Refinement . . . . . . . . . . . 41

V. DISCUSSION • • • • • • • • • • • • • • • • • • • • • 43

Content Description . . . . . . . . . . 43

Factor Patterns . . . . . . . . . . . . 4 4

$\operatorname{Reliability~.~.~.~.~.~.~.~.~.~.~.~.~.~} 48$

Directions for Future Research . . . . . . . . 49

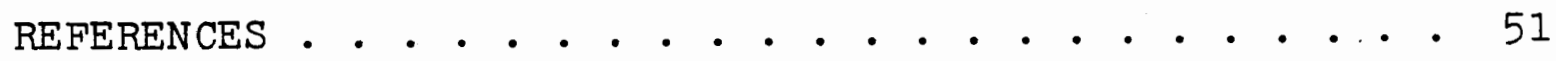

APPENDICES • • • • • • • • • • • • • • • • • • • • 55

A. Initial Structured Interview . . . . . . . . . 56

B. 177-Item Attitude Questionnaire . . . . . . . . 60

C. 80-Item PMAS • . . . . . . . . . . . . . . . 73

D. Psychiatric Medicine Attitude Scale . . . . . . 80 


\section{LIST OF LISTS}

LIST

PAGE

I Directional Differences of Item Responses . . . . 24

II Sample Items . • . . . . . . . . . . . . . 30

III List of 25-Items on Form A of the PMAS . . . . . 31

IV List of 25-Items on Form B of the PMAS . . . . 34 


\section{LIST OF TABLES}

\section{TABLE}

PAGE

I Item Statistics for Form A of the PMAS . . . . 37

II Item Statistics for Form B of the PMAS . . . . 39 


\section{CHAPTER I}

\section{INTRODUCTION}

One of the most valuable contributions clinical research can make to the practice of mental health care is to strengthen the clinician's ability to predict treatment response. It is generally recognized that psychological characteristics of patients play a significant role in determining treatment outcome. Particularly worthy of clinical study are those psychological variables which influence compliance with or adherence to treatment regimen.

Research results provide evidence which indicates that a patient's beliefs and feelings influence his or her treatment adherence, and that by studying the patient's attitudes toward following treatment regimen, rather than the patient's personality, compliance can be predicted (Rosenstock, 1974; Valins \& Nisbett, 1971).

As an exploratory study, the major tasks of this project are threefold: to review the clinical history of compliance, to summarize the theoretical issues regarding the relationship between the patient's attitudes and treatment adherence, and to develop a practical and reliable test to measure a patient's attitude toward taking psychiatric medicine. 


\section{Clinical History of Compliance}

Clinicians find the ability to identify potentially noncompliant patients vital where pharmacological adherence often means the difference between outpatient and inpatient status. Early identification of potential noncompliers increases treatment efficiency by reducing the number and extent of drug trials, conserving medical resources, and encouraging greater involvement of the patient in the treatment regimen. Health educators note that greater patient involvement in treatment results in more rapid recovery (Barsky, 1976; Mathews, 1976).

Three major reviews chronicle the increasing interest In the compliance problem first detailed by Bergman and Werner (1963) and later by Porter (1969). In their book written for the "1974 Workshop/Symposium on Compliance with Therapeutic Regimens," Sackett and Haynes (1976) prepared an annotated bibliography of 246 articles published by 1973. Pothier (1975) compiled a bibliography of 74 references on compliance from the National Library of Medicine. And, most pertinent to this study, using the above studies and an earlier review of his own, Blackwell (1976) extracted and examined 55 articles which concerned compliance with medication regimens of psychiatric patients. 
Magnitude of Compliance and Noncompliance

Compliance is defined generally as, "the extent to which the patient's behavior (in terms of taking medications, following diets, or executing other life-style changes) coincides with the clinical prescription" (Sackett \& Haynes, 1976, p. 1). Compliance with medication regimens is usually measured in terms of rate of omission, some range of medicine-taking defined "compliant" by the investigators, for example, $80 \%$ to $120 \%$ of prescribed daily dosage. Blackwell (1976) found the rate of complete omission (taking no medication at all) among psychiatric outpatients to vary from $25 \%$ to $50 \%$. Compliance as measured by pill count for neurotic outpatients on randomized medication trials was reported to range from $23 \%$ to $54 \%$; the former percentage when compliance was defined as taking all the prescribed medicine, the latter when compliance was defined as intake within $25 \%$ of the prescribed amount (Lipman, Rickels, Uhlenhuth, Park, \& Fisher, 1965; Rickels \& Briscoe, 1970). A study of psychiatric outpatients taking phenothiazines yielded a compliance rate, measured by urine assay, of 65\% (Irwin, Weitzell, \& Morgan, 1971). These studies reveal that clinicians should expect their psychiatric outpatients to comply with medication regimen alone, from between $23 \%$ to $75 \%$ of the time.

Distribution patterns might be as important as adherence rates in determining compliance. A study by 
Gordis, Markowitz, and Lilienfeld (1969) shows a U-shaped distribution of compliance behavior. They found that onethird of the patients were totally noncompliant, one-third took almost all medication prescribed, and the remaining third were scattered in between. The practical implications of a U-shaped distribution pattern of compliance are different than those implied by consideration of a statistically normal distribution curve. To thoroughly evaluate the magnitude of the compliance problem, continued research on distribution pattern as well as average rates is needed. Determinants of Compliance

A review of factors thought to influence compliance supports Porter (1969) in his conclusion that "every patient is a potential defaulter" (p. 222). While this comment may appear cynical, contrary to popular wisdom most helping professionals generally err in predicting their patients' treatment adherence. In the 1976 review by Sackett and Haynes, none of the five articles reporting research on the ability of the therapist to predict patient adherence found any association between therapist predictions and actual patient compliance. Other researchers have corroborated and updated these results with the finding that physicians' accuracy in predicting patient compliance did not improve as familiarity with the patient increased (Roth \& Caron, 1978; Roth, Caron, \& Hsi, 1971). Nevertheless, certain determinants appear regularly in the 
scientific literature on compliance. These variables include certain patient factors, features of the illness, the patient-therapist relationship, features of the medication regimen, and the treatment setting.

patient factors. When correlating demographic factors with keeping scheduled appointment for mixed diagnoses patient samples, most reports in the Sackett and Haynes (1976) review found no link between sex, age, education, marital status, race, nor religion and the compliant behavior. When examining the data for medication adherence alone, Blackwell (1976) found no patient factors which consistently decreased adherence to medical regimens. He did, however, discover four factors which tended to increase treatment compliance: (a) considering the disease a serious one, (b) family stability, (c) compliance with other aspects of treatment, and (d) patient satisfaction with treatment. The family stability factor is related to the variable of supervision by spouse or partner, a factor which dramatically increases medication adherence (Parkes, Brown, \& Monck, 1962; Porter, 1969; Renton, Affleck, Carstairs, \& Forrest, 1963; Willcox, Gillan, \& Hare, 1965). That psychiatric patients, often socially withdrawn, are least compliant of the medical patient population is not surprising in light of these findings.

Features of the illness. Within the general medical patient population, few significant correlations are 
observed between treatment compliance and features of the disease such as severity, duration, previous bouts, recency of last attack, previous hospitalizations, degree of disability, and symptoms. By isolating psychiatric diagnoses in terms of disease severity, duration, and consequences of ceasing medicine, however, identification of noncompliers becomes more possible. In general, psychiatric patients, especially schizophrenics with paranoid features and patients with personality disorders, are significantly less compliant than patients with an organic diagnosis (Sackett \& Haynes, 1976; Wilson \& Enoch, 1967). For psychiatric patients, other investigators found that adherence worsens as the severity of diagnosis increases, suggesting that the ability to cooperate is impaired among the chronic, more disabled patients (Blackwell, 1976). Nonadherence was highest in schizophrenics most ill at time of discharge, for example. The same researchers found that those patients with less severe diagnoses attended outpatient clinics and adhered to medication more faithfully (Renton et al., 1963). Among neurotics, the most anxious outpatients with poorest prognoses and histories of prior treatment elsewhere had lowest adherence (Lipman et a1., 1965).

Besides disease severity, the consequences of stopping medicine are related to noncompliance among psychiatric patients. For example, when patients with diagnoses of 
manic-depressive illness or schizophrenia interrupt their medication regimen, their symptoms do not reappear immediately upon cessation of medicine. Therefore, the consequences of these patients' noncompliance are delayed. Without experiencing an immediate negative consequence, conditions are established which support defaulting rather than medicine-taking. As Blackwell (1973) notes, patients adhere to medication therapies more carefully when relapse is severe or immediate, and tend to be less compliant as the duration of remission increases.

Patient-therapist relationship. Because research has shown patient compliance to be higher in private practice than in clinics, the relationship between patient and therapist is important in the study of compliance (Blackwell, 1972). Although this variable is complex and obviously intercorrelated with the continuity of care topic, certain relevant findings have emerged from the study of the general medical patient population.

Sackett and Haynes (1976) report that the patient's general satisfaction with the therapist and the clinic, and $h$ is or her conclusion that the therapist had met the patient's expectations, both correlate positively with treatment compliance. The specific elements to which patients attend when rating satisfaction or dissatisfaction with their therapist have received little evaluation in scientific literature, however. To date, satisfaction in 
the patient-therapist relationship has been approached from study of contributing environmental characteristics and therapist attitudes primarily. Studies have shown that more positive therapist attitudes toward the patient and toward the role of medicine in treatment, as shown by more positive affective responses, more optimistic treatment prognoses, and a belief in medication as essential, tend to increase patient adherence (Irwin et al., 1971; Shapiro, 1974). An earlier report revealed that therapists with the most compliant patients were more reassuring about side effects and expected gains (Reynolds, Joyce, Swift, Tooley, \& Weatheral1, 1965). Adherence with regimen also declined when a second physician was substituted for the regular caretaker (Becker, Drachman, \& Kirscht, 1972). Again, the above investigations have used general medical populations; unfortunately little research has been published on the therapist-patient relationship as it relates to compliance within a psychiatric population.

Features of the medication regimen. Research on general medical patients has shown consistently that compliance is adversely affected when drugs are given in frequent, divided doses, and when multiple medications are prescribed. In addition, side effects correlate with discontinuing medication, as might be expected (Porter, 1969; Renton et al., 1963). Different compliance rates have been found for alternative drugs and alternate methods of 
administration, but as Sacket and Haynes (1976) note, these findings are inconsistent.

The degree of behavior change required also correlates with adherence. Sackett and Haynes (1976) found a relationship where least behavior change required by the treatment regimen relates to highest regimen compliance, and high required behavior change correlates with lower compliance. It appears that compliance worsens as new medicine taking behavior is required, decreases further if changing old behavior is necessary, and is lowest when breaking personal habits such as smoking or drinking becomes necessary for regimen compliance. This pattern may explain the findings noted earlier of decreased adherence with increasingly complex regimens.

Treatment milieu. In general medicine, adherence can be increased by managing environmental variables such as patient waiting time in the clinic or office, increasing convenience of clinic and pharmacy, and by simplifying intake and scheduling procedures (Irwin et al., 1971; Raynes \& Warren, 1971). Few studies are available on the effect of the treatment setting on compliance for the psychiatric patient. We can assume that factors which exacerbate continuity of patient care and minimize the degree of supervision and support can only have a negative effect upon the patient whose illness reduces his or her awareness of treatment efforts in the first place. 
CHAPTER II

STATEMENT OF THE CLINICAL PROBLEM

The problem of compliance with therapeutic regimen continues to challenge health care professionals. With increasing use of oral medications, more responsibility for self-medication is shifting to the patient at a time when few factors are known to predict clearly compliance behavior. Research has shown that less disabled psychiatric patients with more intact social support systems, enduring relationships with caring health professionals, and simple medication schedules, adhere to treatment plans more consistently than the more disturbed patients who have less social support, less familiar physicians, and more complicated treatment regimens.

Researchers see hope that patient education can increase compliance but results to date are contradictory. In certain cases, medicine compliance increases with more knowledge and instruction, but other reports show the most knowledgeable general medical patients to be the most flagrant noncompliers (Carpenter \& Davis, 1976).

The Health Beliefs Model (HBM) suggests that a patient's motivation to take preventative health action affects compliance with treatment. According to this 
model, factors defining a readiness to act include the patient's perceived susceptibility to the disease, his or her perception of disease severity, the patient's judgment of treatment feasibility and efficacy, and attention to internal and external cues to action (Rosenstock, 1966). Experimental evaluation of the HBM has yielded inconsistent results. Perceived severity of the disease enhanced adherence in cystic flbrosis patients (Meyers, Dolan, \& Mueller, 1975). In hypertensive patients, however, only the perception of the social consequences of being ill predicted compliance (Taylor, cited in Sackett, 1978). Blackwell (1976) suggests that educational strategles like the HBM err in their emphasis on fear as a motivator; he describes the paradoxical effects which result when some patients are urged by threat of debilitation to comply with treatment. Iike the alcoholic driven to drink out of fear of cirrhosis, the noncompliant patient avoids anxiety by forgetting his or her medication, a reminder of sickness. Further contradiction of the assumption that people are motivated by the negative valence of disease is the evidence that illness seems to fulfill an important function in some lives. Examples of patients refusing help abound in clinical literature. See the Simonton's work with cancer patients, Ellerbroek's treatment of acne vulgaris patients, the apparent preference for a grandiose psychosis among some noncompliant schizophrenics, and 
Minuchin's studies of psychosomatic families (VanPutten, Crumpton, \& Yale, 1976; Ellerbroek, 1978; Minuchin, Rosman, \& Baker, 1978; Simonton \& Simonton, 1975).

In those cases where improving compliance is truly beneficial, where as Sackett (1978) states, treatment is known to do more good than harm, where low compliance is a documented problem, and where low compliance interferes with treatment goals, a test inquiring about patient attitudes toward treatment has much practical value. A recent study by Sackett (1977) supports identifying patients' attitudes. Sackett learned that hypertensive patients who admitted noncompliance improved significantly when offered help with medicine-taking strategy. Those who verified their compliance but who were, in fact, not complying, did not improve. It is suggested that surveying attitudes can predict patient compliance with medication regimen.

It is proposed that a Psychiatric Medicine Attitude Scale (PMAS), constructed to measure a patient's attitude toward using psychiatric medicines, will be useful in screening for potential noncompliers among a psychiatric patient population. If an attitude-compliance relationship can be determined, the PMAS will provide an objective index to compare a given patient's attitudes with those of other patients, and will aid in identifying those most likely to benefit from special efforts directed toward compliance with treatment regimen. 
Theoretical Foundations

Through the mid-1960's, social scientists continued to assert the inconsistent relationship between attitudes and behavior. Evidence of the inconsistency began with LaPiere's now classic (although flawed) 1934 study of discrepancy between general attitudes toward minority groups and behavior toward a specific Chinese couple. Since the late 1960 's, however, researchers armed with new theories and methodology have begun to study attitudes with renewed interest and even optimism (Kelman, 1974). Most current investigators accept the existence of an attitude-behavior relationship and concern themselves with the circumstances within which attitudes correlate with behavior. This section will address probability and latent process definitions of attitude, attitude measurement using commitment-free responses, the role of personal and situational variables in the attitude-behavior equation, and attitudes and behavioral compliance in view of the theoretical findings. (General methodological variables have also been found to influence conceptualization of the correlation between attitude and behavior, but their discussion is beyond the scope of this paper. For an excellent review of these factors, the reader is directed to Stewart's 1977 summary.)

Definitions of attitude. DeFleur and Westie (1963) postulate that two general conceptions underlie historical 
definitions of attitude. These categories are probability conceptions and latent process conceptions. Differences between them involve the inferences to be made about attitudinal responses. Adherents of the probability definition state that attitudinal responses are consistent in most situations; behavior toward a specific attitudinal stimulus has a probability of recurring in a particular direction. The latent process definitions take the probability concept a step further and give the behavior a hypothetical anchor. Latent process theorists see attitude as the mediating variable by which consistencies of behavior can be explained. To paraphrase stewart (1977), probability theorists do not expect attitude-behavior consistency across situations because, while attitudes and behaviors might be correlated, they are caused by different variables. Attitude-behavior inconsistency is an issue for the latent process theorists, on the other hand, because, since attitude is for them an intervening variable, it is one of the causes of behavior.

Attitude measurement using commitment-free responses.

The purpose of defining attitude is to enable its measurement. This investigation used a model for attitude measurement based on latent process theory. Goodmonson and Glaudin in 1971 proposed a suitable paradigm which used as a measurement criterion the amount of commitment a response carries. They proposed that response consequences lie on a commitment-free to committed behavior continuum. In the 
Goodmonson and Glaudin model, attitude is a latent or intervening variable which can be inferred from commitment-free responses to an attitude test. Because attitude is viewed as one of the causes of behavior, in this model attitude-behavior inconsistency can be attributed to the impact of other variables on behavior.

Using the latent process definition of attitude, the problem of measuring attitudes toward psychiatric medicine becomes one of developing a reliable instrument which would permit commitment-free responses concerning the referent subject. Much attitude research has examined racial, political, and religious issues, subjects which are constrained by powerful social behavioral guidelines. In comparison, the topic of psychiatric medicine is relatively free of inherent social expectancies and therefore seems an appropriate psychological object for attitude research.

Personal and situational variables. Before the mid-1960's, personal and situational variables were deemed error variance in most attitude research (Fishbein, 1967). More recently, researchers have begun to include investigation of personal and situational variables in their examinations of the attitude-behavior correlation (Iiska, 1975). Empirical evidence supports this theoretical shift. In her review, Stewart (1977) found that personal variables such as verbal skills, intellectual and social abilities, activity level, self-perception as a doer, ego involvement, and deliberate inconsistency, influenced the 
attitude-behavior relationship. While intuitively and empirically, individual factors appear to affect behavior, a computer-aided literature search yielded no reports of studies concerning the effect of these types of personal variables on attitudes of psychiatric patients.

Attitudes have been further categorized as attitudes toward the specific object, toward the action itself, and toward the situation (Kelman, 1974). Normative beliefs also have been suggested as a situational variable which may influence the attitude-behavior relationship (Fishbein, 1967).

On the basis of previous literature, this author expected attitudes toward psychiatric medicine, toward taking psychiatric medicine, and toward being in a situation in which psychiatric medication therapy is indicated, to be some of the attitudinal variables which interact with certain personal variables to influence a psychiatric patient's medicine-taking. Further, beliefs of his or her peer or cultural groups likely influence the individual's attitude toward the referent object. It would be efficacious to include these variables in any examination of the factors thought to affect the attitude-behavior correlation.

Attitudes and compliance. As noted earlier, latent process attitude theory suggests that attitude is one of the intervening and personal variables which have been found to influence any action situation. It also was noted that a 
literature review revealed that the topic of attitudes of psychiatric patients toward specific aspects of psychiatric medicine and psychiatric medicine-taking has been ignored by scientific journals. Other research suggests that attitude toward psychiatric medicine can be determined from responses to a commitment-free questionnaire. This study proposed to develop an attitude scale for use in future research examining the effect of attitudes on psychiatric patients' medicine-taking behavior. Attitude theory and data from empirical investigations indicate that such a scale would be enhanced by inclusion of statements concerning attitudes toward psychiatric medicine, toward taking such medication, toward being required to take psychiatric medication, and influences from the normative group.

If a reliable questionnaire were devised, this would be a tool to facilitate research on several unanswered questions. An attitude questionnaire would be useful in determining the parameters of a psychiatric patient's attitudes toward his or her therapy, would allow comparisons of the patient to other groups, and would initiate the study of the influence of attitude on compliance with prescribed therapy regimen. Given good validity data, potential uses of an attitude scale would include the differentiation of patients likely to be non-compliers from the remaining psychiatric population. 


\section{CHAPTER III}

\section{METHOD}

\section{Part I-Scale Development}

Subjects. The development of the questionnaire item pool began by interviewing 15 patients undergoing medical and psychological treatment for depression and anxiety in various treatment facilities. Inpatient facilities included a rural state hospital 20 miles from a mediumsized city in the Pacific northwest and a Veteran's Administration Hospital in that city. The other setting was a private outpatient clinic operated by a psychiatrist and a clinical psychologist in the same city. The average age of the eight female patients was 39.6 years, of the seven males, 34.9 years. Of these patients, five women and six men had prior psychiatric medicine experience. Instrument. A structured interview was constructed which covered specific and general attitude content dimensions. The interview included questions regarding general attitude toward taking psychiatric medicine, vulnerability toward illness, efficacy of psychiatric medicine, pleasant and unpleasant aspects of psychiatric medicine, schedule followed when prescribed medicine, factors which enhanced or inhibited schedule adherence, 
changes experienced if any, and attributions about the changes when taking psychiatric medicine or failing to take psychiatric medicine (see Appendix A).

Analysis and development of scale for Part II. Upon analysis, patient responses to the structured interview appeared to fall into six content dimensions: fear of physical addiction, fear of emotional dependency, the use of psychiatric medicine as covering up problems, risk versus safety of the medicine, trust in the helping professional, and obligation or duty to take prescribed medicine. To generate additional material, concepts from attitude and health education literature were used to supplement the above data. Questions in four areas, the influence of significant others, belief in medicine efficacy, the need for information about the medicine, and the belief that medicine improved cognitive efficiency, were added. Finally, items from the Health Belief Model were included as the 11th content dimension (Rosenstock, 1974). These latter items concerned general health motivation, perceived susceptibility toward the illness, perceived severity of the illness, and probability that compliant behavior would reduce threat of illness. All items were constructed using as much original wording from the structured interview data as possible. Sentences were written in brief and self-referent form. (See Appendix B for a copy of this 177-item questionnaire.) 
The 177 items were evaluated by eight health care professionals for expression of positive, negative, or ambiguous attitude toward psychiatric medicine, after Thurstone (1931). Judges' agreement about expression of valence was tabulated for each item. Four items consistently judged positive and four judged negative were extracted from each content dimension, building a list of 80 items. (See Appendix C for 80-item PMAS.) The Health Belief Model items yielded inconsistent ratings from the judges and were deleted from the item pool at this stage.

\section{Part II-Scale Refinement}

Subjects. Subjects for the scale refinement phase were 126 introductory psychology college students enrolled at a metropolitan state university in the same city mentioned earlier, and 30 outpatients receiving medical and psychological treatment for depression and anxiety in the previously noted clinic. Questionnaires with more than 10 percent of the questions unanswered were discarded. Six student questionnaires and one outpatient form were unusable, resulting in usable questionnaires from 149 subjects.

Of these, 65 subjects met the criterion for inclusion in the "experienced" sample; the criterion for inclusion was experience regarding psychiatric medicine, either reported personal experience and/or experience through that of a close friend or relative. The experienced subjects ( 30 
outpatients and 35 students) included 33 females and 32 males, mean ages of 32.33 years. The naive subjects, $\underline{\mathrm{n}}=$ 84, included 43 females and 41 males with an average age of 23.88 years. The experienced subjects as a group were significantly older $(\underline{p}<.001)$ than the medicine-naive subjects.

Instrument. The 80-item PMAS was used. Items were rated on a six point scale from "strongly agree" (1) to "strongly disagree" (6). An informed consent form was attached to each questionnaire following university procedure. Although signatures were required on the consent forms, anonymity was secured by detaching the consent forms from the questionnaires before data analysis.

Procedure. Students were administered the questionnaire during regular class time. Subjects from the outpatient clinic completed the questionnaire at the time of their initial visit. Questionnaires typically required 10 minutes for completion. Data collection proceeded for six months from December 1978 through May 1979.

Analysis. The resulting data were analyzed in a four step process of scale refinement.

The descriptive data were analyzed first. Frequency distributions of item responses were examined and responses of the experienced and naive subjects were contrasted on a per item basis using two-tailed t tests.

Then, correlation matrices for the 80 PMAS items were computed for each group separately (experienced = E, and 
naive $=N$ ) and together $(T)$. The three resulting $80 \times 80$ matrices were factor-analyzed using the principle components method. After initial factoring, the factors having eigenvalues of 1.000 and greater were rotated to an orthogonal Kaiser normalized Varimax solution for each group. Prominent factor patterns were noted.

Third, factor patterns from the $E, N$, and $T$ data were compared. Items with loadings of $: 40$ and greater were selected from prominent and content-similar factors for $\mathrm{E}$ and $T$ groups. Alternate forms, designated Forms $A$ and $B$, comprised of 25 items each were developed.

Finally, Pearson product-moment correlations were computed to examine the item-total correlations for each of the preliminary 25-item versions of the PMAS. The 25-item scales were pared to 20-item final versions. Alternate form reliability was computed by correlating total scores of the 20-item version of Form A with that of Form B. 
CHAPTER IV

RESULTS

The following results were obtained from responses of the 149 subjects to the 80-item PMAS. Results from each step of scale development, analysis of descriptive data, factor analyses, alternate form construction, and scale refinement, are described.

Descriptive Data

Item means ranged from 1.70 to 5.20 on the six point scale from strongly agree (1) to strongly disagree (6). The experienced subjects expressed consistently greater response variability than did the naive subjects.

The experienced subjects responded in a significantly different direction, $\underline{p}<.01$, than the naive subjects on $54 \%$ of the items. List I shows examples of items on which the $E$ mean response differs from that of the $N$ mean response.

To summarize their differences, the experienced subjects tended to agree with items which expressed more confidence in medical help, more willingness to follow medication directions, less fear of possible physical and cognitive side-effects from psychiatric medication, less fear of addiction, and less concern about social censure 


\section{IIST I}

\section{DIRECTIONAL DIFFERENCES OF ITEM RESPONSES}

$\underline{\bar{x}_{\mathrm{E}}} \quad \overline{\mathrm{x}}_{\mathrm{N}} \quad$ E subjects agreed more than $\mathrm{N}$ subjects:

1.491 .92 If psychiatric medicine were prescribed for me, I would follow the directions carefully.

2.862 .46 I feel it would be necessary for me to comply with a prescription for psychiatric medication. (10)

2.913 .42 I would put up with some uncomfortable medication side-effects in order to get over a serious depression. (14)

3.31 3.75 Psychiatric medicine might give me the energy to think clearly if I were depressed. (18)

2.37 2.99 I think some problems can be faced up to better with the support of psychiatric medications. (36)

3.023 .38 I would take psychiatric medication prescribed for me because I think it is pretty effective. (40)

4.43 4.79 When I have emotional problems, I want psychiatric medicine prescribed for me. (48)

2.343 .01 I take my medication regularly regardless of what my family thinks of it. (53)

2.002 .62 I think it's always best to seek medical help for severe depression. (61)

2.56 3.21 Psychiatric medicines which are prescribed by a doctor have been carefully screened by scientific studies. (65)

3.524 .18 I have no qualms about trying psychiatric medication my doctor recomends. (68)

2.43 3.10 I think a patient should take prescribed psychiatric medicine even if family and friends don't understand. (69)

3.974 .55 I'll try whatever psychiatric medicine my doctor recommends.

(72)

2.31 2.81 Other people's opinions would never stop me from taking the medication I need. (80) 
$\overline{\mathrm{x}}_{\mathrm{E}} \quad \overline{\mathrm{x}}_{\mathrm{N}} \quad$ E subjects disagreed more than $\mathrm{N}$ subjects:

3.623 .15 Psychiatric medicines usually cover up problems that should be faced.

4.253 .64 Even carefully prescribed psychiatric medicines are much too risky. (9)

4.553 .70 I don't believe in psychiatric medicines.

2.94 2.56 Psychiatric medications are habit-forming.

3.803 .13 I believe all psychiatric medicines present a very real danger of addiction. (16)

5.605 .23 Whether you take prescribed psychiatric medicine exactly as directed just isn't very important. (17)

3.422 .98 I believe people should face their problems without psychiatric medicine. (19)

5.15 4.57 Unless friends kept encouraging me to take prescribed psychiatric medicine, I would stop. (22)

4.033 .56 I would not take prescribed psychiatric medicines because they take the edge off my thinking. (24)

4.77 4.25 The only value psychiatric medicine has comes from the power of suggestion. (26)

3.742 .89 I'm afraid that if I took a prescribed psychiatric medicine, I would become dependent on it. (28)

2.541 .94 A patient should reject psychiatric medication unless every detail is explained carefully. (30)

3.082 .60 I think it's wrong to take medicine all the time because if your thinking is dulled, you don't have a good sense of when you're wel1. (31) (Item withdrawn from consideration.)

3.492 .96 Having to take psychiatric medicines is no way to live.

(33) 


\section{LIST I ( con'd)}

$\underline{\bar{x}_{\mathrm{E}} \quad \overline{\mathrm{x}}_{\mathrm{N}}}$

5.064 .37 I would not take prescribed psychiatric medication even if every detail were explained to me. (37)

4.88 4.46 If my family seemed uninterested in my treatment, I would throw prescribed psychiatric medicine down the sink. (42)

5.004 .33 I would not take psychiatric medication prescribed for me if my family and friends seemed very interested. (44) (Item withdrawn from consideration.)

3.71 3.31 I believe psychiatric medication usually makes thinking fuzzy. (45)

2.061 .60 I would be hesitant to take psychiatric medication prescribed for me without knowing all about it. (47)

4.88 4.18 I don't care how safe a psychiatric medication is reported to be, I still wouldn't take it. (50)

4.583 .74 I believe psychiatric medicines basically poison the body. (54)

4.68 4.17 Psychiatric medicines are too weak to help treat big problems. (58)

2.772 .27 I see psychiatric medicine as a last resort to coping with emotional problems. (63)

3.983 .24 You can't expect a patient to take psychiatric medication if no one cares. (64)

3.77 2.95 Even though psychiatric medicine might help with emotions, it usually makes it harder to think clearly.

(67)

3.973 .36 I think psychiatric medications almost always block you from having feelings you should experience. (70) 


\section{LIST I ( con'd)}

$\underline{\bar{x}_{\mathrm{E}}} \quad \overline{\mathrm{x}}_{\mathrm{N}}$

3.663 .13 Once you begin taking psychiatric medicine, it is hard to give it up. (73)

4.85 4.26 All the medical information in the world couldn't convince me to take psychiatric medication. (75)

Note. $\quad 1$ = strongly agree; $6=$ strongly disagree. Numbers in parentheses at the end of each item indicate the item number on the 80-item PMAS. 
regarding taking prescribed psychiatric medicine, than did the medicine-naive subjects.

Factor Analyses

An examination of the factor patterns for the experienced and naive subjects and for the total group was made for the purpose of selecting items for the final scale. In this process, somewhat more emphasis was placed on the results of the factor pattern of the experienced subjects. This was done because of the observation that many patients beginning psychiatric outpatient treatment had had prior somatic therapy elsewhere (Glaudin, 1979). It seemed likely that the attitude patterns of the medicine-experienced subjects would correlate best with those of the population on which the questionnaire eventually would be used. In developing the content dimensions, those prominent factors from the pattern of the experienced subjects which included at least two items with high and/or similar loadings were selected. The latter criterion was used for the purpose of developing two alternate forms. Corroboration of the resulting content dimensions was sought within the factor patterns of the total group. The factor patterns of the total sample appeared to parallel considerably the ten factors from the experienced subject sample. 
Analysis of the factor patterns yielded ten prominent factors. These were labeled, (a) information, (b) dangers, (c) coping, (d) need, (e) remembering, (f) addiction, (g) details, (h) friends, (i) authority, and, (j) emotions. List II shows sample items from each factor.

Alternate Form Construction (25-item PMAS)

Through the process of factor analysis described in the methods section, items suitable for inclusion in alternate forms of a preliminary (25-item) PMAS were derived. A number of quantitative and qualitative criteria for item selection were used. Desirable items were those which (a) met Thurstone (1931) analysis criteria (low ambiguity), (b) represented all categories of endorsement, (c) represented the 10 content dimensions, and (d) had varying degrees of content specificity. In addition, items on which the experienced subjects differed significantly from the medicine-naive subjects were balanced with items on which the two groups responded similarly. The last criterion was style, with briefer and self-referent items being preferred. Iists III and IV show the 25 items of Forms $A$ and $B$ of the PMAS.

As can be seen from Tables I and II, three items (53, 56 , and 63) of the final 50 selected did not have loadings on . 40 or higher in the factor pattern of the total group. 
1. Information

Once I had the medical facts carefully explained to me, I would take necessary psychiatric medication.

2. Dangers

I think psychiatric medicines usually have bad side effects.

3. Coping Psychiatric medicine can help provide the energy to face overwhelming problems.

4. Need

I would take psychiatric medication I needed whether I liked the doctor or not.

5. Remembering

It is easy for me to neglect taking my medication when I get busy.

6. Addiction

Psychiatric medications are habit-forming.

7. Details

A patient should reject psychiatric medication unless every detail is explained carefully. (Omitted in final PMAS.)

8. Friends

Unless friends kept encouraging me to take prescribed psychiatric medicine, I would stop. (Omitted in final PMAS. )

9. Authority

I have no qualms about trying psychiatric medication my doctor recommends.

10. Emotions

I would be relieved to find out that a close friend was taking medication for depression. 


\section{IIST III}

LIST OF 25-ITEMS ON FORM A OF THE PMAS

\section{Factor 1. Information}

Once I had the medical facts carefully explained to me, I would take necessary psychiatric medication. (35)

I would not take prescribed psychiatric medication even if every detail were explained to me. (37)

I think a patient should take prescribed psychiatric medicine even if family and friends don't understand. (69)

I don't believe in psychiatric medicines.

I would put up with some uncomfortable medication sideeffects in order to get over a serious depression.

Even carefully prescribed psychiatric medicines are much too risky.

I would take psychiatric medication prescribed for me because I believe it is pretty effective. (40)

The trouble with psychiatric medicines is that they just don't work.

(38)

Factor 2. Dangers

Once you begin taking psychiatric medicine, it is hard to give it up. (73)

I think psychiatric medicines usually have bad side effects.

Even though psychiatric medicine might help with emotions, it usually makes it harder to think clearly. 
Factor 3. Coping

I believe prescribed psychiatric medicines usually would make a patient's thinking clearer because of less anxiety. (74)

Psychiatric medicine can help provide the energy to face overwhelming problems. (46)

I believe psychiatric medications can make it possible to learn new behavior in frightening situations.

Factor 4. Need

I would take prescribed psychiatric medication for the sake of my loved ones.

It would be impossible for me to take psychiatric medicine from a doctor I didn't trust. (62) Omitted

Factor 5. Remembering

It is easy for me to neglect taking my medication when I get busy. (55)

No matter how busy I get, I always remember to take my medication on time. (43) Omitted

Factor 6. Addiction

Carefully prescribed psychiatric medicines have no danger of addiction. (41) Omitted

Whether you take psychiatric medicine exactly as prescribed just isn't very important.

Factor 7. Details

A patient should reject psychiatric medication unless every detail is explained carefully. (30) Omitted 
Factor 8. Friends

Unless friends kept encouraging me to take prescribed psychiatric medicine, I would stop. (22) Omitted

Factor 9. Authority

I would take psychiatric medication prescribed for me and not worry about scientific details. (56)

I have no qualms about trying psychiatric medication my doctor recommends. (68)

Factor 10. Emotions

I would be relieved to find out that a close friend was taking medication for depression. (15)

Note. Numbers in parentheses at the end of each item indicate the item number on the 80-item PMAS. 


\section{IIST IV}

LIST OF 25-ITEMS ON FORM B OF THE PMAS

Factor 1. Information

Having the scientific information would influence me to take psychiatric medication prescribed for me. (39)

I don't care how safe a psychiatric medication is reported to be, I still wouldn't take it. (50)

If the doctor explains what effects the medicine might have on me, I would take it as prescribed. (59)

All the medical information in the world couldn't convince me to take psychiatric medication.

I think some problems can be faced up to better with the support of psychiatric medications. (36)

Psychiatric medicines usually cover up problems that should be faced.

I think taking psychiatric medicine is a realistic method to lessen discomfort. (20)

I would rather have psychological counseling forever than take psychiatric medicines. (23)

Factor 2. Dangers

I'm afraid that if I took a prescribed psychiatric medicine, I would become dependent on it. (28)

I believe psychiatric medication usually makes thinking fuzzy. (45)

I think psychiatric medications almost always block you from having feelings you should experience.

(70)

Factor 3. Coping

Psychiatric medicine might give me the energy to think clearly if I were depressed.

(1)

I think prescribed psychiatric medication can help patients concentrate better.

(52) 
Frequently, patients can learn new ways of coping because psychiatric medicines break up old anxiety patterns. (66)

Factor 4. Need

I would take psychiatric medication I needed whether I liked the doctor or not. (60)

I would never take psychiatric medicine from a doctor I didn't have full confidence in. (27) Omitted

Factor 5. Remembering

It would be easy for me to forget to take my medicine. (76) Omitted

I take my medication regularly regardless of what my family thinks of it. (53)

Factor 6. Addiction

One of the best things about most psychiatric medication is that there is no risk of addiction.

Psychiatric medications are habit-forming.

Factor 7. Details

A patient should reject psychiatric medication unless every detail is explained carefully. (30) Omitted

Factor 8. Friends

Unless friends kept encouraging me to take prescribed psychiatric medicine, I would stop. (22) Omitted 


\section{LIST IV (con'd)}

Factor 9. Authority

I'Il try whatever psychiatric medicine my doctor recommends. (72)

I would be hesitant to take psychiatric medication prescribed for me without knowing all about it. (47)

Factor 10. Emotions

I see psychiatric medicine as a last resort to coping with emotional problems. (63) Omitted

Note. Numbers in parentheses at the end of each item indicate the item number on the 80-item PMAS. 


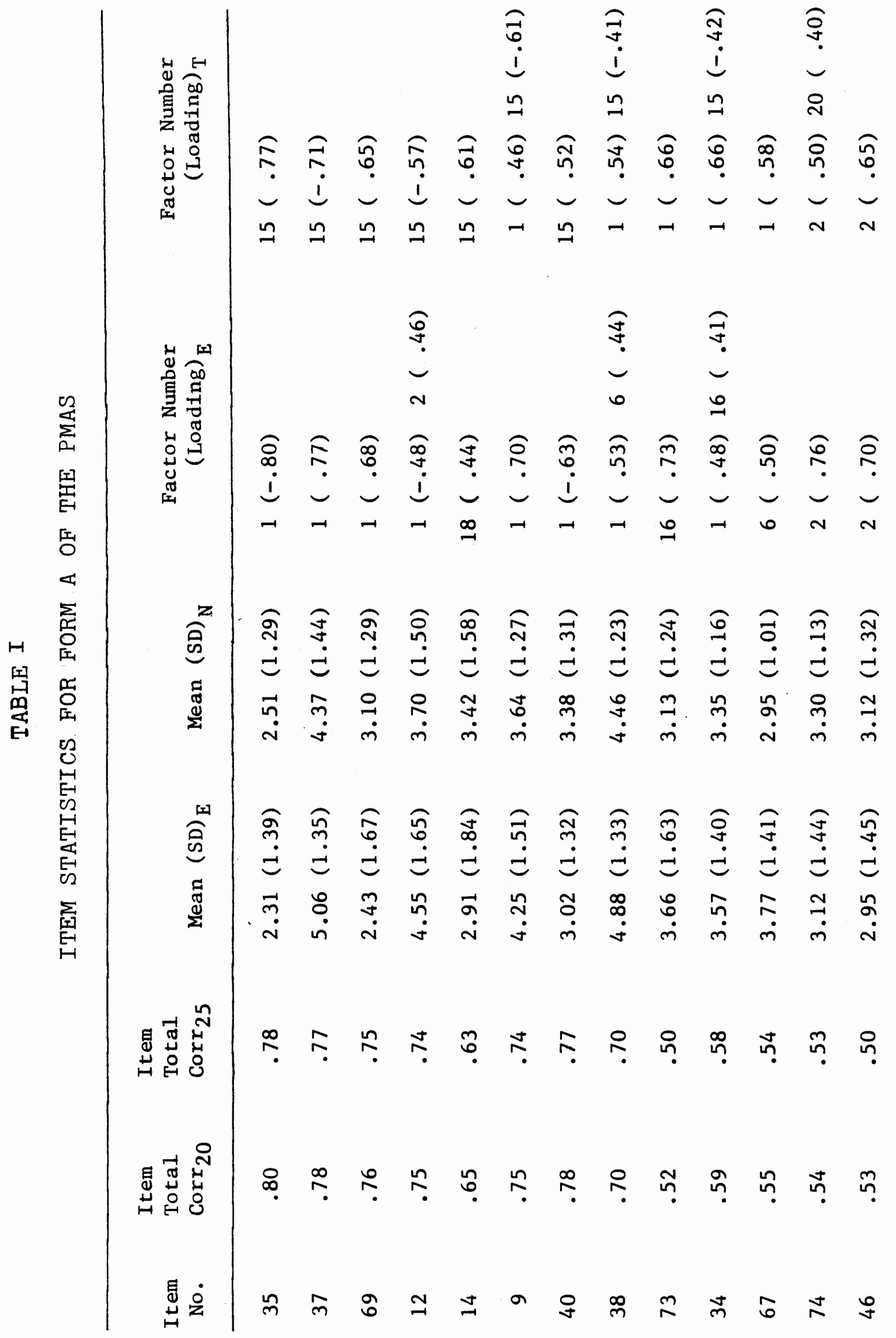




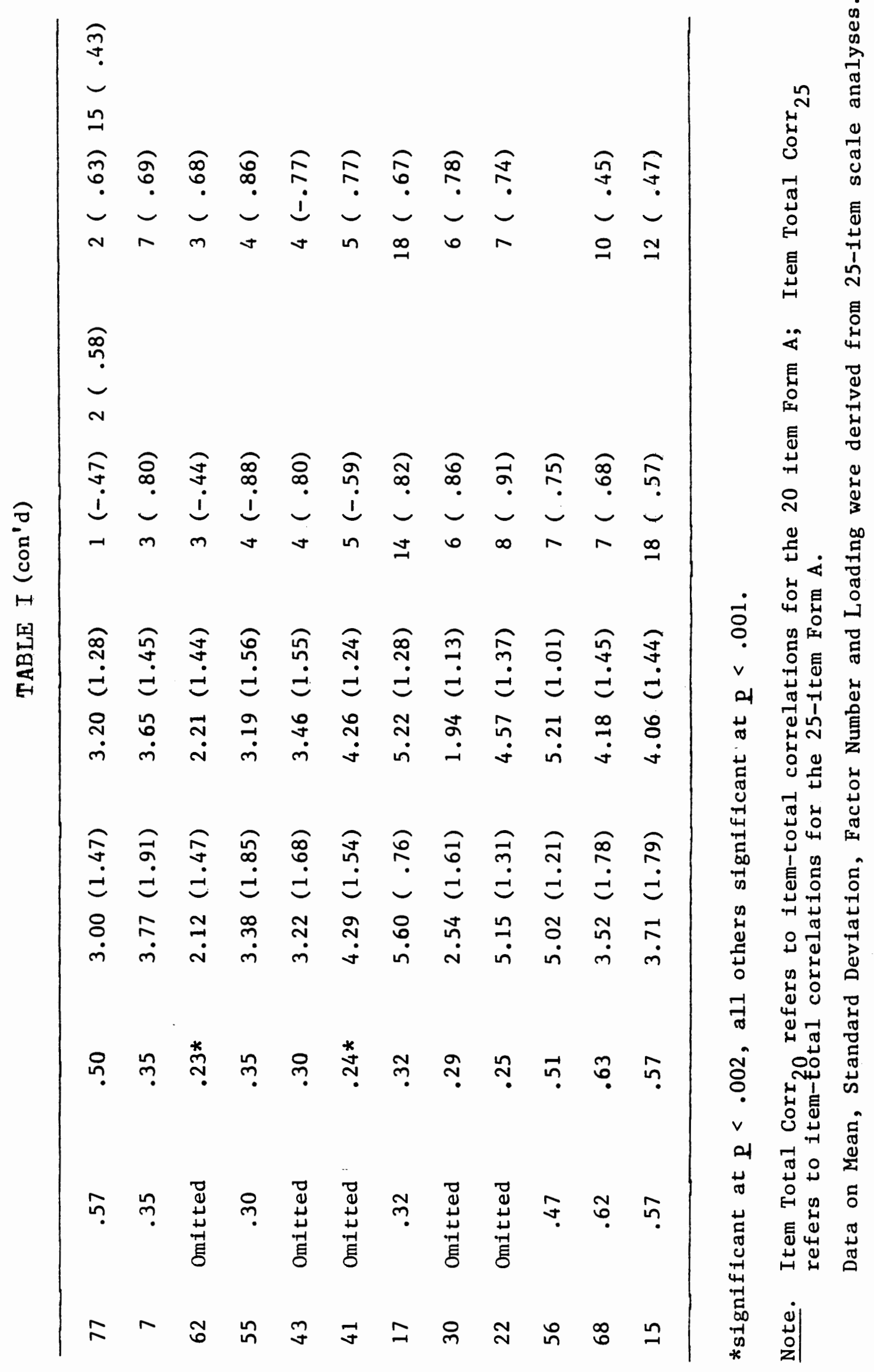




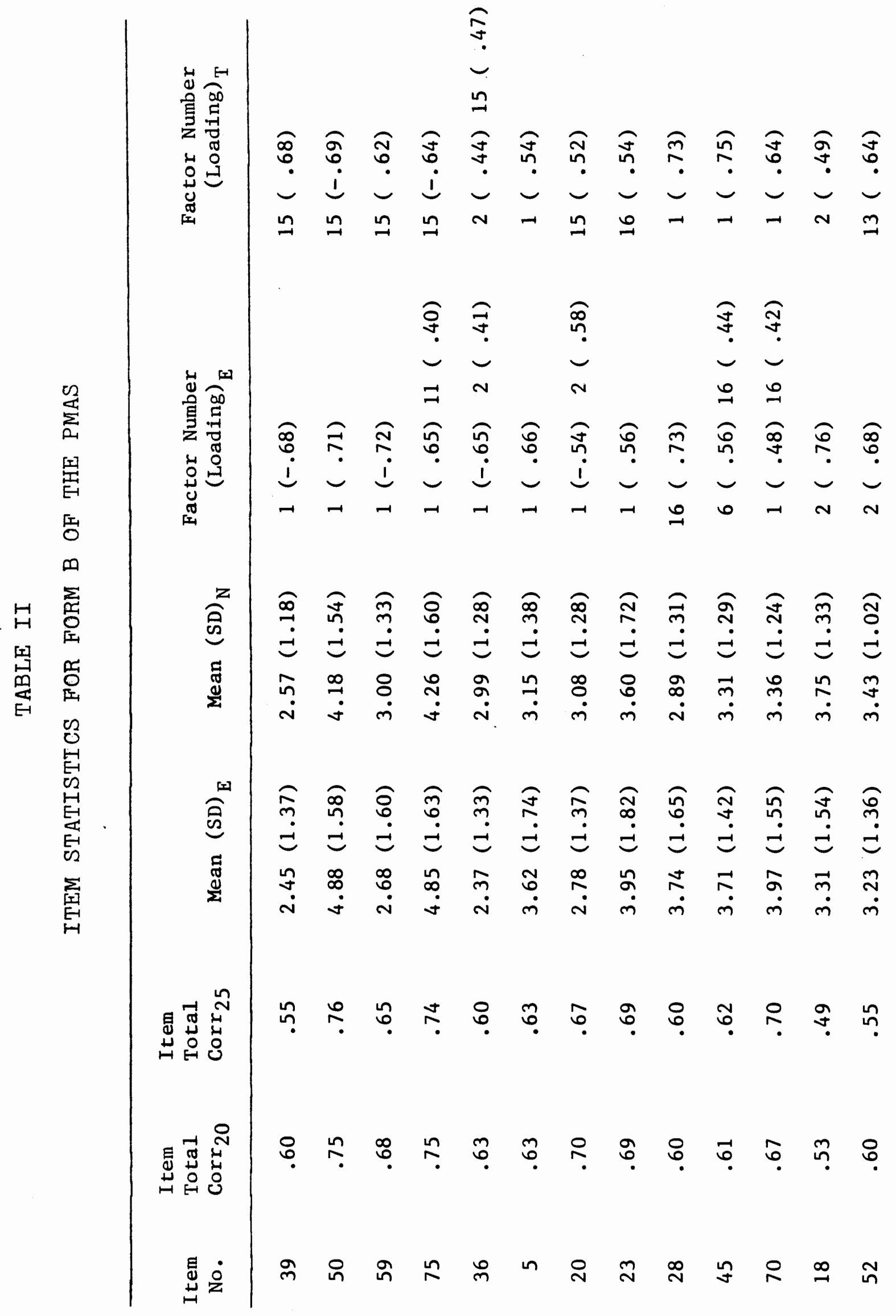




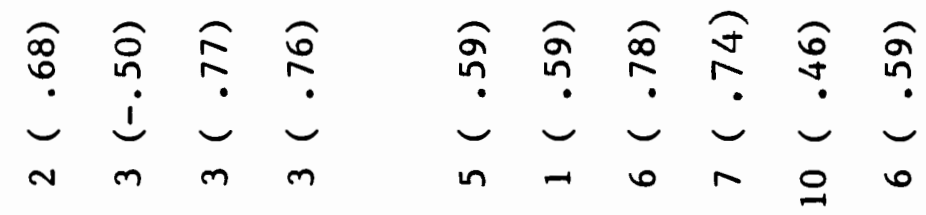

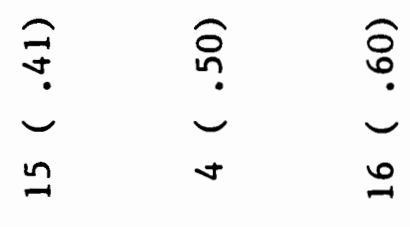

กิ

$\because i \quad i \quad i \quad i \quad i \quad j \quad i \quad i$

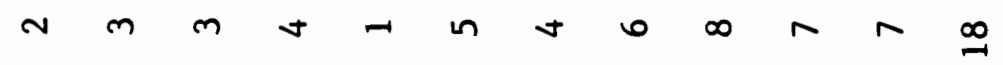

כૈ

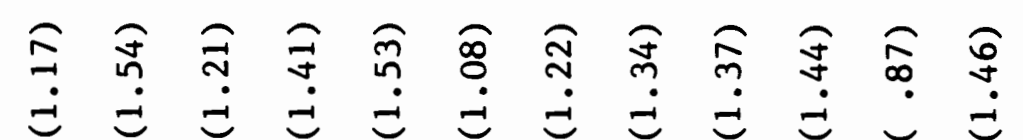

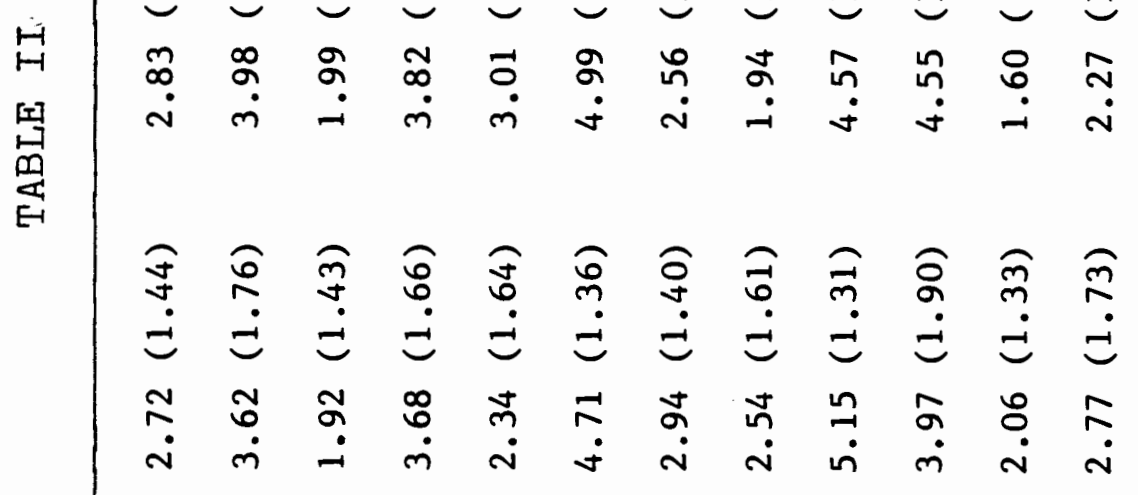

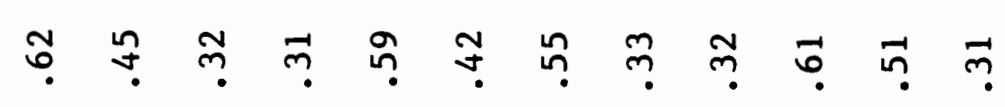

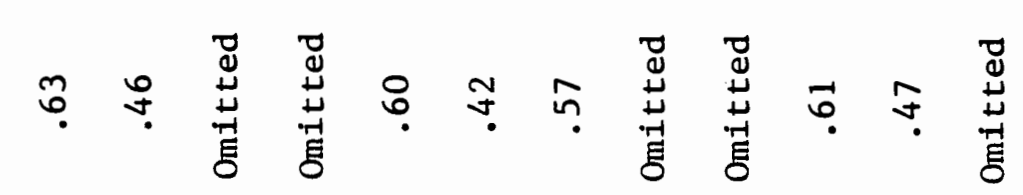

\begin{tabular}{lll}
$n$ & $\frac{\pi}{2}$ \\
0 & 0 \\
0 & 0 \\
0 & 0 \\
\hline & 0
\end{tabular}

ㅇำกำ 
Scale Refinement

To reduce the time required for completion of the PMAS, the number of attitude questions was limited to 20 on each form. Pearson product-moment correlations were performed on each 25-item form. Item-total correlations for the 25-item Form A ranged from .78 to .23 with a median correlation of .54. Item-total correlations for the 25-item Form B ranged from .76 to .31 with a median of .60 .

The five items having the lowest correlations with total score were deleted from each scale. As Table II shows, items $22,30,41,43$, and 62 were omitted from the 25-item Form A. Items 22, 27, 30, 63, and 76 were dropped from the 25-item Form B.

Pearson product-moment item-total correlations were rerun on the 20-item scales. The item-total correlations on the final version of Form A ranged from .80 to .30 with a median correlation of .58. The 20-item Form B item-total correlations ranged from .75 to .42 , and had a median correlation of .62. (See Appendix D for copies of the 20-item PMAS scales.)

These calculations reflect the moderate to strong degree of internal consistency of each scale. Reliability between the 20-item Forms $A$ and $B$ was .93, significant at the $\underline{p}<.001$ level. The mean score for the experienced subjects on the 20 items which comprise Form A was 2.85, and on the 20 which make up Form B, was 3.17. The mean 
score for the naive subjects on the 20-item Form A was 3.40 and on the Form B, was 3.51. Again, greater response variability of the experienced subjects was noted. In summary, reliability checks showed adequate internal reliability between the alternate forms. These data demonstrate that the task of developing an easily administered and reliable commitment-free instrument to measure attitudes toward psychiatric medicine among medicine-experienced and medicine-naive patients was accomplished. 
CHAPTER V

\section{DISCUSSION}

These results describe the development of a paper and pencil scale evaluating attitudes toward psychiatric medicine. The investigation revealed that several content dimensions emerged from the data on attitudes. It also appeared that individuals with prior personal or vicarious experience with the referent object tended to respond to the questionnaire in a qualitatively different manner and with more variability of endorsement per item than did those with no prior psychiatric medicine experience. Scientific literature indicates the possibility of predicting behavior once attitudes, as measured on a commitment-free instrument, are known. This section will discuss content of the attitude dimensions, the factor patterns which resulted, reliability of the results obtained, as well as directions for future research with, and use of, the PMAS.

\section{Content Description}

As noted earlier, the medicine-experienced subjects responded differently than did the medicine-naive subjects to the instrument. In general, although their response variability wäs greater, the experienced subjects responded more positively toward the referent topic. The more 
positive response pattern was evident in both general and specific item content. Experienced individuals disagreed strongly (mean responses of 4.55 and 4.58 , respectively) with global items such as, "I don't believe in psychiatric medicines," and, "I believe psychiatric medicines basically poison the body." At a more specific content level, they agreed (mean responses 1.49 and 2.00 , respectively) with items of this type: "If psychiatric medicine were prescribed for me, I would follow the directions carefully," and, "I think it's always best to seek medical help for severe depression."

A closer examination of the descriptive statistics shows the more positive attitude of the experienced group to have several components. The experienced group endorsed items which indicated (a) willingness to comply with medication instructions, (b) belief in the efficacy of psychiatric medicine (specifically that it helps one face problems and permits clear thinking), (c) trust in the scientific information about the safety of psychiatric medicine, (d) disregard for possible somatic or cognitive side-effects, (e) minimal fear of addiction to psychiatric medicine, and, ( $f$ ) disregard of social censure for taking psychiatric medicines. These findings suggest that previous experience with the attitude object minimizes some general prejudices about psychiatric medicine, such as that 
it covers up problems, clouds one's thinking and is addictive.

In discussing the more positive attitudes of the experienced subjects, it is important to note again the mean age differences between the two samples. The experienced subjects tended to be in their early $30^{\prime}$ s and the naive subjects tended to be in their early 20's. The influence of age in this measurement of attitude toward psychiatric medicine remains unclear. Since the group of medicine-experienced subjects is relatively $\operatorname{small}(\mathrm{n}=65)$ the argument could be made that a restricted sample was obtained. However, it is likely that, as a function of living independently and facing life's traditional stressors such as jobs and significant relationships for a longer period of time, more people in the older sample will have sought psychiatric help for emotional problems than in the younger group. It is possible that experience with the referent or therapy in general as well as a tendency to think more flexibly as one matures, apparent in their more varied responses, fostered the more positive attitude shown by this sample of medicine-experienced individuals. While it is also possible to speculate that the attitudes of the older, experienced subjects had evolved from a more negative position such as that endorsed by the younger, naive subjects, it is impossible to verify this hypothesis without a longitudinal study or at least a retrospective pretest. Even then, the validity of the latter could be 
questioned. The former was unfortunately outside the realm of this research and will remain for future investigations.

Information about dimensions of attitudes toward psychiatric medicine and differences in attitude as a function of experience or age could be useful to professionals who treat psychiatric patients. If validity work on the PMAS establishes a relationship between attitude toward psychiatric medicine and compliance with therapeutic regimen, scale results could help close the gap between therapists' assumptions and patients' behavior noted in the introduction of this report.

These results imply that the patient-doctor relationship is important in subtle ways as the patient builds experience with psychiatric medicine. The large body of psychological research on placebo effects supports this implication. Attitudes could be influenced by how the patient is treated by the prescribing professional, the professional's confidence in the medicine, the competence and caring shown by the staff; it could be that simple conditioning accounts for the attitudes expressed and that any internal stimulus or external event contiguous to the medicine-taking could influence the regard with which the individual holds the experience. This is a fertile area for research. In any case, it is obvious that the patient-doctor relationship carries much potential for influencing beliefs and thoughts. It seems plausible that 
these influences affect behavioral intentions toward psychiatric medicine and treatment adherence.

Factor Patterns

Because of the modest sample size, generalizations from the factor analyses are presented as suggestions for dimensions of attitude patterns. The results of this study show clearly, however, that the attitudes toward psychiatric medicine are multidimensional. The relationship between positive and negative attitudes is not simply a linear one stretching from positive feelings at one pole and negative attitudes on the opposite. Rather the options surveyed seem rich and intercorrelated. In addition, responses of individuals with different medicine-taking histories suggest future differences in commitment behavior, such as compliance with medication regimens and perhaps even therapy outcome.

The factor patterns basically support the original 10 experimental content dimensions. For our samples, attitudes toward psychiatric medicine include these dimensions: feelings about trusting scientific information about psychiatric medicine, (b) fears of somatic and cognitive dangers from taking psychiatric medicine, (c) belief that medicine helps one handle problems of living, (d) need for the medication, (e) feelings about remembering to take prescribed medication as directed, ( $f$ ) beliefs about psychiatric medicine's potential for addiction, (g) need to 
have details about the medicine explained, (h) feelings about the influence of friends and family upon medicine-taking behavior, (i) belief in the attending authority to prescribe the best medicine for the patient, and $(j)$ belief in the efficacy of medicine for specific complaints such as depression or anxiety.

The PMAS attempted to capture the complexity of these attitudes by representing these content dimensions in the final version of the scale. This project is an initial study, and it is hoped that future research will investigate the accuracy and predictive validity of the content dimensions of the scale. Of special interest is a model of the attitude structure of compliant and noncompliant patients. The factors obtained in this investigation begin to outline the range and content of attitudes patients have toward psychiatric medicine. These analyses suggest that the development of a cognitive model for attitudes toward psychiatric medicine is possible. Even before extensive validity testing of the instrument and development of norms, it appears that the PMAS can have utility in a clinical setting.

$\underline{\text { Reliability }}$

As noted in the results section, the internal and alternate forms consistency was good. The scale was found to be a reliable instrument for the sample tested. 
Directions for Future Research

As noted earlier, the validation of the PMAS remains to be done. In addition, the results obtained in this investigation suggest several areas for continued research with the scale.

Because the normative sample is small, the development of more extensive norms is advised. It is also suggested that future research focus on verifying the reliability through more extensive standardization and investigating more thoroughly the affective components of attitude. It is expected that obtaining PMAS scores on a larger number of medicine-experienced patients will produce a somewhat lower response variability within this group as a whole. Standardization on a larger sample would also permit more extensive examination of the factor patterns found in this exploratory work. If a relationship is found between positive attitude as measured by the PMAS and compliance with regimen, it will be interesting to evaluate the differences in the attitude factors endorsed by both experienced and naive individuals. More conclusive evaluation of the factor patterns would be possible given larger norms.

Another area for future research is in the development of specific scales or subscales for different presenting complaints. For example, factor 10 was interesting because the only apparent relationship among its items was that each sentence contained the word "depression" or the word 
"anxiety." This suggests that these specific words cue certain beliefs or feelings, indicating possible differences in the patterns of attitudes about general psychiatric treatment and treatment for specific complaints such as anxiety or depression. If validity work results in the expected relationships between attitude and treatment compliance, it might prove useful to develop separate scales for different presenting disorders. Since in attitude measurement, it is believed that the more specific the referent topic, the more predictive the scale, PMAS's for complaints of depression, pain, or anxiety, could have definite clinical utility (Kelman, 1974). 


\section{REFERENCES}

Barsky, A. J. III. Patient heal thyself: Activating the ambulatory medical patient. Journal of Chronic Diseases, $1976, \underline{29}, 585-597$.

Becker, M. H., Drachman, R. H., \& Kirscht, J. P. Predicting mothers' compliance with pediatric medical regimens. Journal of Pediatries, 1972, 81, 843-854.

Bergman, A. B., \& Werner, R. J. Failure of children to receive penicilin by mouth. New England Journal of Medicine, 1963, 268, 1334-1338.

Blackwell, B. The drug defaulter. Clinical and Pharmacological Therapeutics, 1972, 13, 841-848.

Blackwell, B. Drug therapy: Patient compliance. New England Journal of Medicine, 1973, 289, 249-252.

Blackwell., B. Treatment adherence. British Journal of Psychiatry, 1976, 129, 513-531.

Carpenter, J. O., \& Davis, L. J. Medical recommendations-Followed or ignored? Factors influencing arthritis. Archives of Physical Medicine and Rehabilitation, 1976, 57, 241-246.

DeFleur, M. L., \& Westie, F. R. Attitude as a scientific concept. Social Forces, 1963, 42, 17-31.

Ellerbroek, W. C. Language, thought and disease. CoEvolution Quarterly, 19.78, 17, 30-38.

Fishbein, M. Readings in attitude theory and measurement. New York: W1ley, 1967.

Glaudin, V. Personal communication, 1979.

Goodmonson, C., \& Glaudin, V. The relationship of commitment-free behavior and commitment behavior: A study of attitude toward organ transplantation. Journal of Social Issues, 1971, 27, 171-183.

Gordis, L., Markowitz, M., \& Lilienfeld, A. M. Why patients don't follow medical advice: A study of children on long-term antistreptococcal prophylaxis. Journal of Pediatrics, 1969, 75, 957-968. 
Irwin, D. S., Weitzell, W. D., \& Morgan, D. W. Phenothiazine intake and staff attitudes. American Journal of Psychiatry, 1971, 127, 1631-1635.

Kelman, H. C. Attitudes are allve and well and gainfully employed in the sphere of action. American Psychologist, $1974, \underline{29}, 310-335$.

Lapiere, R. T. Attitudes vis. action. Social Forces, 1934, $13,230-237$.

Lipman, R. S., Rickels, K., Uhlenhuth, E. H., Park, L. C., \& Fisher, $S$. Neurotics who fail to-take their drugs. British Journal of Psychiatry, 1965, III, 1043-0149.

Liska, A. E. (Ed.). The consistency controversy: Readings on the impact of attitudes on behavior. New York: Halstead Press, 1975.

Mathews, B. Introduction. In, J. W. Cullen, B. H. Fox, \& R. N. Isom (Eds.), Cancer: The behavioral dimension. New York: Raven Press, 1976.

Meyers, D., Dolan, T. F., \& Mueller, D. Compliance and self-medication in eystic fibrosis. "American Journal of Diseases of the Child, 1975, 129, 1011-1013.

Minuchin, S., Rosman, B. L., \& Baker, L. Psychosomatic families: Anorexia nervosa in context. Cambridge, Massachusetts: Harvard University Press, 1978.

Parkes, C. M., Brown, G. W., \& Monck, E. M. The general practitioner and the schizophrenic patient. British Medical Journal, 1962, ii, 972-976.

Porter, A. M. W: Drug defauting in a general practice. British Medical Journal, 1969, 1, 218-222.

Pothier, P. E. Patient compliance in therapy--Bibliography . National Library of Medicine, 1975.

Raynes, A. E., \& Warren, G. Some characteristics of "dropouts" at first contact with a psychiatric clinic. Community Mental Health Journal, 1971, I, 144-150.

Renton, C. A., Affleck, J.W., Carstairs, G. M., \& Forrest, A. D. A follow-up of schizophrenic patients in Edinburgh. Acta Psychiatrica Scandinavica, 1963, 39, 548-600. 
Reynolds, E., Joyce, C. R. B., Swift, J. L., Tooley, R. H., \& Weatherall, M. Psychological and clinical investigation of the treatment of anxious outpatients with three barbiturates and placebo. British Journal of Psychiatry, 1965, III, 84-95.

Rickels, K., \& Briscoe, E. Assessment of dosage deviation in outpatient drug research. Journal of Clinical Pharmacology, 1970, 10, 153-160.

Rosenstock, I. M. Why people use health services. Milbank Memorial Fund Quarterly (Part II), $1966,44,92-1 \overline{24 .}$

Rosenstock, I. M. Historical origins of the Health Belief Model. Health Education Monographs, 1974, 2, 1-8.

Roth, H. P., \& Caron, H. S. Accuracy of doctors' estimates and patients' statements on adherence to a drug regimen. Clinical Pharmacology and Therapeutics, 1978, 23, $361-370$.

Roth, H. P., Caron, H. P., \& Hsi, B. P. Estimating a patient's cooperation with his regimen. The American Journal of the Medical Sciences, 1971, 262, 269-297.

Sackett, D. L. Compliance trials and the clinician. Archives of Internal Medicine, 19.7.8, 138, 23-25.

Sackett, D. I. Why won't patients take their medicine? Canadian Family Physician, 1977, 23, 462-262.

Sackett, D. L., \& Haynes, R. B. (Eds.). Compliance with therapeutic regimens. Baltimore: Johns Hopkins University Press, 1976.

Shapiro, R. J. Therapist attitudes and premature termination in family and individual therapy. Journal of Nervous and Mental Diseases, 1974, 159, 101-107.

Simonton, O. C., \& Simonton, S. S. Belief systems and the management of the emotional aspects of malignancy. Journal of Transpersonal Psychology, 1975, 7, 29-47.

Stewart, B. The relationship between attitude and behavior: Implications for service provision for the elderly. Unpublished manuscript, Institute on Aging, Portland State University, 1977 .

Taylor, D. W. In press, cited in, Sackett, D. L. Patients and therapies: Getting the two together. New England Journal of Medicine, $1978, \underline{298}, 278-279$. 
Thurstone, L. L. The measurement of social attitudes. Journal of Abnormal and Social Psychology, 1931, 26, 249-269.

Valins, S., \& Nisbett, R. E. Attribution processes in the development and treatment of emotional disorders. New York: General Learning Press, 1971.

VanPutten, T., Crumpton, E., \& Yale, C. Drug refusal in schizophrenia and the wish to be crazy. Archives of General Psychiatry, 1976, 33, 1443-1446.

Willcox, D. R. C., Gillan, R., \& Hare, E. H. Do psychiatric outpatients take their drugs? British Medical Journal, 1965, ii, 790-792.

Wilson, J. D., \& Enoch, M. D. Estimation of drug rejection by schizophrenic inpatients, with analysis of clinical factors. British Journal of Psychiatry, 1967, 113, $209-211$. 


\section{APPENDICES}


APPENDIX A

INITIAI STRUCTURED INTERVIEW 
INITIAI COMPIIANCE INTERVIEW WITH PSYCHIATRIC OUTPATIENTS

We are involved in a research study investigating how people feel about taking psychiatric medicine. This study is designed to find out the relationship between attitude and following the medication directions.

Your information is a critical part of this study. From the information you give us, we hope to build the basic questionnaire of the study. The questionnaire developed from your information will be used to survey a large number of people who, for differing reasons, are taking psychiatric medicine. The interview has 16 questions about how you feel about taking medicine, what things help you take it on time, what prevents you from taking it, and what changes you feel because of the medicine.

During this interview, we hope that you will represent your own thinking and feelings, as well as what you think others believe.

Do you have any questions? If not, let's start the interview.

1. In general, how would you describe your attitude toward taking psychiatric medicine?

1a. What do you think about other people taking psychiatric medicine?

1b. What do you think of taking medication for nervousness (anxiety), depression, or sleeplessness?

2. Some people feel vulnerable to illness. 
2a. In general, how likely is it that you become ill?

2b. If you do get sick, how severe do you expect the illness to be?

2c. How worried would you be if a close friend your age became depressed?

3. To what extent do you feel that taking psychiatric medicine is helpful in treating depression?

4. Taking medicine has some aspects that are more pleasant than others.

4a. What about taking psychiatric medicine is pleasant?

4b. What about taking psychiatric medicine is unpleasant?

5. When you are given a prescription, what kind of schedule do you tend to follow for taking the medicine?

6. What sorts of things prevent you from taking medication as prescribed? 
7. What kinds of things help you with taking the medicine on schedule?

8. What kinds of changes do you experience when you take psychiatric medicine that has been prescribed for you?

8a. If there has been a change in the way you felt since beginning treatment, to what do you attribute these changes?

9. What changes occur when you fail to take psychiatric medicine that has been prescribed for you?

10. Is there anything else that I've forgotten to ask you about taking psychiatric medicine? 
APPENDIX B

177-ITEM ATTITUDE QUESTIONNAIRE 
MEASURING ATTITUDES TOWARD TAKING PSYCHIATRIC MEDICATION

Questions for reviewers:

1. Is the item readable? If not, how could it be improved?

2. Does the item express a positive or negative attitude? Please put a plus sign, minus sign, or a question mark in front of each item to tell us if you think the attitude conveyed is positive, negative, or unclear, respectively.

3. What content areas have we left out? 
1. PHYSICAL ADDICTION

Carefully prescribed psychiatric medicines have no danger of addiction.

One of the best things about most psychiatric medications is that there is no risk of addiction.

I would be able to take psychiatric medications as prescribed with no risk of addiction.

I believe all psychiatric medicines present a very real danger of addiction.

I think most people tend to become physically dependent on the psychiatric medications prescribed for them.

I'm afraid that if I took a prescribed psychiatric medicine, I would become dependent on it.

I would take prescribed psychiatric medicine for a few days only.

Most prescribed psychiatric medicines are safe to take over a period of months.

I could take prescribed psychiatric medicines without becoming dependent on them.

Psychiatric medications are habit-forming.

Once you begin taking psychiatric medicine, it is hard to give it up.

It is too easy to become dependent upon psychiatric medicine.

I think it's unlikely that someone my age would become dependent upon psychiatric medicine.

I think most people are afraid of the possibility of drug dependency.

I would not worry about becoming addicted to a psychiatric medicine prescribed for me.

I feel certain that taking psychiatric medicine for more than just a few days leads to physical dependency upon it.

I'd be very afraid of getting hooked on psychiatric medicines. 
2. EMOTIONAL DEPENDENCY VS. STOIC INDEPENDENCE

I don't like relying upon medication to solve emotional problems.

I would prefer to put up with my problems rather than take psychiatric medicine.

I'd tend to rely on psychiatric medication less than other people do to solve my problems.

Psychiatric medicine is only an emotional crutch.

It is too easy for me to depend upon psychiatric medication to handle my emotions.

I would be relieved to find out that a close friend was taking medication for depression.

I believe people should face their problems without psychiatric medicine.

I believe a person should be strong enough to live without psychiatric medications.

Anyone who has chronic depression anticipates any help they can get to relieve it.

I handle all my' problems without help from others.

I don't believe in psychiatric medicines.

I would rather suffer than use psychiatric medicine.

I'm against psychiatric medicine because it is just a crutch.

Psychiatric medication can help with all kinds of problems. Taking psychiatric medication is not the moral way to live. I would rather take psychiatric medicine than be extremely depressed.

When I have emotional problems, I want psychiatric medicine prescribed for me. 
I think taking psychiatric medicine means you are weak.

In my opinion, taking psychiatric medicine is a lot better

than having constant anxiety.

I would rather commit suicide than take prescribed psychiatric medicine.

Having to take psychiatric medicines is no way to live.

I would be disgusted to find out that a friend of mine was taking psychiatric medication.

Letting the depression run its natural course is the right way to get well.

I think it's always best to seek medical help for severe depression.

My life is too short to spend it suffering from emotional problems.

I know that if I needed psychiatric medication to live, I would consent to it.

A person would be a fool not to take psychiatric medicine when he really needs it.

Taking psychiatric medicine would prove that I can't handle my problems on my own.

3. COVER UP PROBLEMS VS. LEARN-FACE-FACILITATE

Psychiatric medicines usually cover up problems that should be faced.

I think some problems can be faced up to better with the support of psychiatric medications.

I believe psychiatric medications can make it possible to learn new behavior in frightening situations.

Frequently, patients can learn new ways of coping because psychiatric medicines break up old anxiety patterns.

I would rather rely on psychological help and not take psychiatric medications prescribed for me.

Psychiatric medication can help provide the energy to face overwhelming problems. 
Frequently, psychiatric medication counteracts

discouragement so patients can tackle tough problems.

I think psychiatric medications make people too comfortable to face their problems.

Psychiatric medicines seem to reduce people's motivation for new learning.

I think psychiatric medications almost always block you from having feelings you should experience.

I believe psychiatric medicines are prescribed too easily for routine problems.

I would rather have psychological counseling forever than take psychiatric medicines.

I see psychiatric medicine as a last resort to coping with emotional problems.

Psychiatric medicine is there to make life easier for you. Taking psychiatric medicine conceals the problem.

It's important to realize the limitations of psychiatric medicine.

\section{INFLUENCE OF SIGNIFICANT OTHERS}

I would take prescribed psychiatric medication for the sake of my loved ones.

If my family seemed uninterested in my treatment, I would throw prescribed psychiatric medicine down the sink.

Unless friends kept encouraging me to take prescribed psychiatric medicine, I would stop.

You can't expect a patient to take psychiatric medication if no one cares.

I think a patient should take prescribed psychiatric medicine even if family and friends don't understand.

I take my medication regularly regardless of what my family thinks of it. 
If my family encouraged me, I would take psychiatric medication prescribed for me.

If my spouse took medication regularly, I would be more inclined to take mine.

My family always insisted that I take the medication recommended by my doctor.

I would not take psychiatric medication prescribed for me if my family and friends seemed very interested.

I prefer to follow my family's guidance about taking psychiatric medication.

I would avoid the advice of friends in considering psychiatric medicines for my problems.

Other people's opinions would never stop me from taking the medication I need.

\section{EFFICACY}

Prescribed psychiatric medications are usually effective. Psychiatric medicines do little good in relieving important symptoms.

I would take prescribed psychiatric medicines if they were more effective than they are.

I would take psychiatric medication prescribed for me because I believe it is pretty effective.

Psychiatric medicines are too weak to help treat big problems.

The best thing about psychiatric medicines is that they work.

The trouble with psychiatric medicines is that they just don't work.

It's really all in your head; if you think a psychiatric medicine is going to work, it will work.

The only value psychiatric medicine has comes from the power of suggestion. 
Being more relaxed is something you can count on from taking psychiatric medicines.

Psychiatric medicines can help us return to a more normal way of living.

I think taking psychiatric medicine is a realistic method to lessen discomfort.

I see taking psychiatric medicine as necessary to a better functioning body.

I'm convinced that it isn't natural to reduce emotional suffering by using psychiatric medication.

I think it's a sad waste to deny a person the medicine necessary to good emotional health.

I think people should take psychiatric medicine if they're anxious and nervous.

I see psychiatric medicine as a powerful tool in treating depression and nervousness.

If I can't sleep, or if I get a headache, a mild tranquilizer is a good idea.

\section{RISK VS SAFETY}

Prescribed psychiatric medicines are not like other dangerous drugs which harm the body.

Even carefully prescribed psychiatric medicines are much too risky.

Psychiatric medicines do much more good than any minor harm they may cause.

I believe psychiatric medicines basically poison the body.

I think psychiatric medicines usually have bad side effects.

I don't think psychiatric medicines are safe enough to be used with human beings.

The risk of suicide is much greater than any risk in prescribed psychiatric medications.

I would put up with some uncomfortable medication side effects in order to get over a serious depression. 
In my opinion, any negative side effects are minor compared to the good psychiatric medications do.

Patients should be willing to put up with some physical discomfort from psychiatric medicines if the medicines can help.

I believe psychiatric medicines are too dangerous.

Even if a side effect is found in only one out of 100 patients, I still would not take psychiatric medications.

I don't care how safe a psychiatric medication is reported to be, I still wouldn't take it.

By the time a psychiatric medication is ready to be used in practice, it is safe.

Psychiatric medicines which are prescribed by a doctor have been carefulliy screened by scientific studies.

I can't accept the idea of ingesting chemicals, even in small doses, into my body.

7. INFORMATION (OBSESSIVE) VS. NAIVETE

A patient should reject psychiatric medication unless every detail is explained carefully.

Once I had the medical facts carefully explained to me, I would take necessary psychiatric medication.

All I need to know about psychiatric medicines is whether the doctor thinks I should take them.

I would not take prescribed psychiatric medication even if every detail were explained to me.

I would take psychiatric medicine prescribed for me and not worry about scientific details.

If the doctor explains what effects the medicine might have on me, I would take it as prescribed.

I would be hesitant to take psychiatric medication prescribed for me without knowing all about it.

All the medical information in the world couldn't convince me to take psychiatric medication. 
Having scientific information could influence me to take psychiatric medication prescribed for me.

8. TRUST VS. MISTRUST IN HELPING PROFESSIONAL

I would take psychiatric medicine if I trusted the doctor who prescribed it.

If the doctor listened to me carefully, I would take the psychiatric medicine he gave me.

I would follow through on taking psychiatric medicine if I liked the way the doctor treated me.

Nothing is more important than trusting the doctor who prescribes medicine for me.

It would be impossible for me to take psychiatric medicine from a doctor I didn't trust.

If I did't like a doctor, I would reject medicine he wanted me to take.

No one should take psychiatric medicine from an obnoxious doctor.

I would take psychiatric medication I needed whether I liked the doctor or not.

I would not take medicine from a doctor who was disrespectful.

I believe in taking prescribed medicine even if the doctor seems uncaring.

I'll try whatever psychiatric medicine my doctor recommends.

I have no qualms about trying psychiatric medication my doctor recommends.

I think most people trust their doctors to know about medications.

I would never take psychiatric medicine from a doctor I didn't have full confidence in.

I've always felt it was important to follow doctor's orders about medication.

If I have faith in my doctor, I always take the medication prescribed for me. 
Having a doctor who cares is the first step toward getting well.

I've never taken medicine out of worry about the doctor's opinion.

I would take psychiatric medications prescribed by a competent doctor even if he seemed uncaring.

9. CAREFULNESS/GUILT/DUTY VS. CASUALNESS

I feel guilty when I don't take prescribed medications on schedule.

I trust my own judgement about when to take my medication rather than following a schedule.

I take my medicine when I feel like taking it.

I never take my medicine before I think I need it, no matter what the written instructions are.

I get a guilty conscience if I don't follow my medication instructions.

My conscience nags me if I don't take my prescribed medicine.

I think it is my duty to take psychiatric medication prescribed for me.

I would feel guilty if I didn't take psychiatric medication prescribed for me.

Psychiatric medications should be taken if a doctor prescribes them.

I think it would be easy for me to take prescribed psychiatric medicine.

I certainly don't think a patient should feel guilty for rejecting prescribed psychiatric medicine.

Whether you take prescribed psychiatric medicine exactly as directed just isn't very important.

If psychiatric medicine were prescribed for me, I would follow the directions carefully.

I might sample psychiatric medication prescribed for me. 
I feel it would be necessary for me to comply with a prescription for psychiatric medication.

It is easy for me to neglect taking my medication when I get busy.

No matter how busy I get, I always remember to take my medication on time.

Although I have good intentions, it's hard to remember to take my medicine regularly.

Sometimes I can forget my medication when I am too busy.

10. COGNITIVE EFFICIENCY

Psychiatric medicine can increase a patient's ability to think clearly about his problems.

I think prescribed psychiatric medication can help patients concentrate better.

I believe psychiatric medication usually makes thinking fuzzy.

Even though psychiatric medicine might help with emotions, it usually makes it harder to think clearly.

I would not take prescribed psychiatric medicines because they would take the edge off my thinking.

I believe prescribed psychiatric medicines usually would make a patient's thinking clearer because of less anxiety.

Psychiatric medicine might give me the energy to think clearly if I were depressed.

I think it's wrong to take medicine all the time because if your thinking is dulled, you don't have a good sense of when you're well.

11. HEALTH BELIEF MODEL DIMENSIONS (Please continue to rate items for expression of positive, neutral, or negative attitude toward psychiatric medicine.)

A) GENERAL HEALTH MOTIVATION

I am very concerned about getting sick.

The possibility of my getting sick is very low. 
I buy special foods to improve and protect my health.

I do not take vitamins regularly.

Compared to other people, I do more things to keep well.

B) PERCEIVED SUSCEPTIBIIITY/SEVERITY

I tend to be more likely than others to get sick.

In general, I am less vulnerable to illness than other people my age.

When I do get sick, my illness tends to interfere with my daily activities.

When I become ill, I do not tend to get severely ill.

I have had much experience with emotional illnesses.

C) PROBABIIITY THAT COMPLIANT BEHAVIOR WILI REDUCE THREAT

I believe that psychiatric medication is safe.

Most psychiatric medicine is not helpful in treating emotional problems.

I generally have faith in doctors and medical care.

My chances for recovering from emotional illness are poor. 
APPENDIX C

80-ITEM PMAS 
I, , hereby agree to serve

as a subject in the research project on Measuring Attitudes Toward Psychiatric Medicine, conducted under the supervision of Vincent Glaudin, Ph.D., and Barbara Stewart, Ph.D.

I understand that the study involves filling out a questionnaire about my attitudes. I understand that possible risks to me associated with this study are losing ten minutes of class time.

It has been explained to me that the purpose of the study is to learn about attitudes toward psychiatric medication, and about how these attitudes might affect a person's behavior in ereatment. I may not receive any direct benefit from participating in this study, but my participation may help to increase knowledge which may benefit others in the future.

Kathryn Paris has offered to answer any questions I may have about the study and what is expected of me in the study.

I understand that I am free to withdraw from participation in this study at any time without feopardizing either my grade in this class or my relationship with Portland State University.

I have read and understand the foregoing information.

Date Signature

If you experience problems that are the result of your participation in this study, please contact Richard Streeter, Office of Graduate Studies and Research, 105 Neuberger Hall, Portland State University, 229-3423. 
PSYCHIATRIC MEDICINE ATTITUDE SCALE

I. Demographics

Please $f i l l$ in or check the appropriate response:

Age in years

Sex: Male

Female

Check the statement that applies to you:

I have taken prescribed psychiatric medicine in the past but an not currently taking it.

I am currently raking prescribed psychiatric medicine.

I have never taken prescribed psychiatric medicine.

II. Instructions

Circle the letter which best corresponds to the way you feel about each statement.

Example

The PSU library needs to be open more hours.

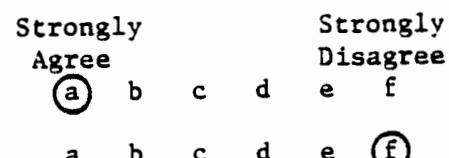

I think that public college tuition should be rafsed.

a $\quad b \quad c \quad d \quad e$

(f)

\section{Questionnafre}

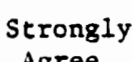

1. In my opinion, any negative side effects are minor Agree Disagree compared to the good psychiatric medications do.

2. The best thing about psychiatric medicines is that 2 . a b $c$ d e f they work.

3. I'm convinced that it isn't natural to reduce 3. $a$ b c d e f emotional suffering by using psychiatric medication.

4. I never take my medicine before I think I need it, 4 . a b $c$ d e f no matter what the written instructions are.

5. Psychlatric medicines usually cover up problems 5 . a b c d e f that should be faced.

6. If I didn't like a doccor, I would reject medicine 6 . a b c d e f he wanted me to take.

7. I would take prescribed psychiatric medication for 7 . a b c d e f the sake of wy loved ones.

8. If psychiatric medicine were prescribed for me, $I$ 8, a b c d e E would follow the directions carefully. 
9. Even caretully prescribed psychiatric medicines are much too risky.

10. I feel it would be necessary for me to comply with a prescription for psychiatric medication.

11. I would take psychlatrfc medications prescribed by a competent doctor even if he seemed uncaring.

12. I don't belleve in psychiatric medicines.

13. Psychiatric medications are habit-forming.

14. I would put up with some uncomfortable medication side effects in order to get over a serious depression.

15. I would be relieved to find out that a close friend was taking medication for depression.

16. I believe all psychiatric medicines present a very real danger of addiction.

17. Whether you take prescribed psychiatric medicine exactly as directed just isn't very important.

18. Psychiatric medicine might give me the energy to think clearly if I were depressed.

19. I belleve people should face their problems without 19. a b c d e f psychiatric medicine.

20. I think taking psychiatric medicine is a realistic method to lessen discomfort.

21. Une of the best things about most psychiatric medications is that there is no risk of addiction.

22. Unless friends kept encouraging me to take prescribed psychiatric medicine, I would stop.

23. I would rather have psychological counseling forever than take psychiatric medicines.

24. I would not take prescribed psychiatric medicines because they take the edge off my thinking.

25. Psychiatric medicine can increase a patient's ability to think clearly about his problems.

26. The only value psychiatric medicine has comes from the power of suggestion.

27. I would never take psychiatric medicine from a doctor I didn't have full confidence in.

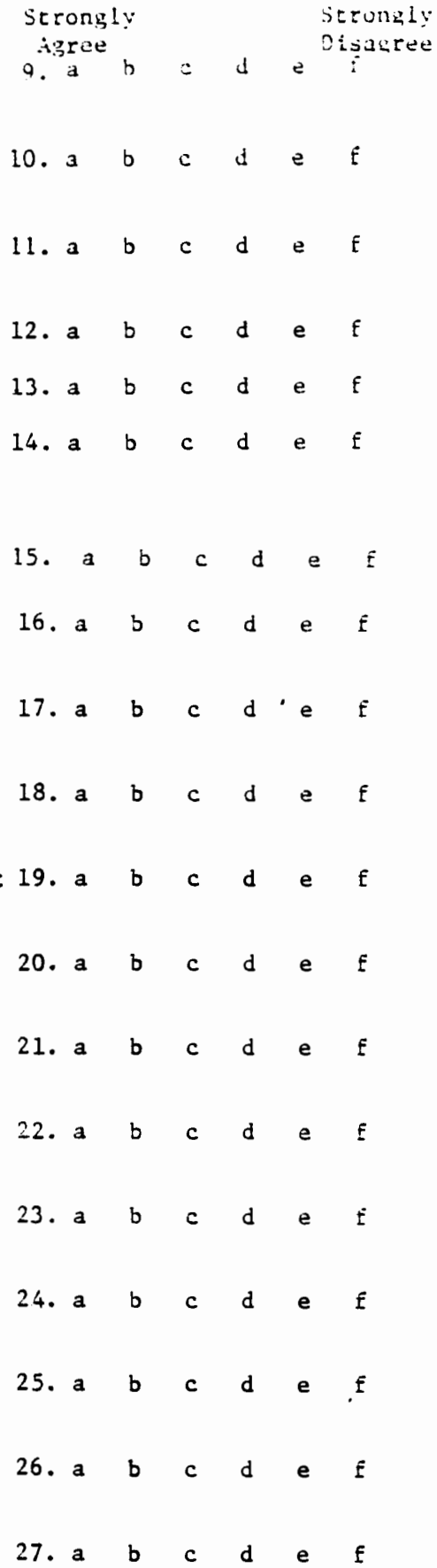


28. I'm afraid that if I took a prescribed psychiatric medicine, I would become dependent on it.

29. Psychtatrtc medication can help with all kinds of problems.

30. A patient should reject psychiatric medication unless every detail is explained carefully.

31. I think it's wrong to take medicine all the time because if your thinking is dulled, you don't have a good sense of when you're well.

32. I could take prescribed psychiatric medicines without becoming dependent on them.

33. Having to take psychiatric medicines is no way to live.

34. I think psychiatric medicines usually have bad side effects.

35. Once I had the medical facts carefully explained to ine, I would take necessary psychiatric medication.

36. I think some problems can be faced up to better with the support of psychiatric medications.

37. I would not take prescribed psychiatric medication even if every detail were explained to me.

38. The trouble with psychiatric medicines is that they just don't work.

39. Having the scientific information would influence me to take psychiatric medication prescribed for me.

40. I would take psychiatric medication prescribed for the because I believe it is pretty effective.

41. Carefully prescribed psychiatric medicines have no danger of addiction.

42. If my family seemed uninterested in my treatment, I would throw prescribed psychiatric medictne down the sink.

43. No matter how busy I get, I always remember to take my medication on-time.

44. I would not take psychlatric medication prescribed to me if my family and friends seemed very interested.

45. I belleve psychiatric medication usually makes thinking fuzzy.

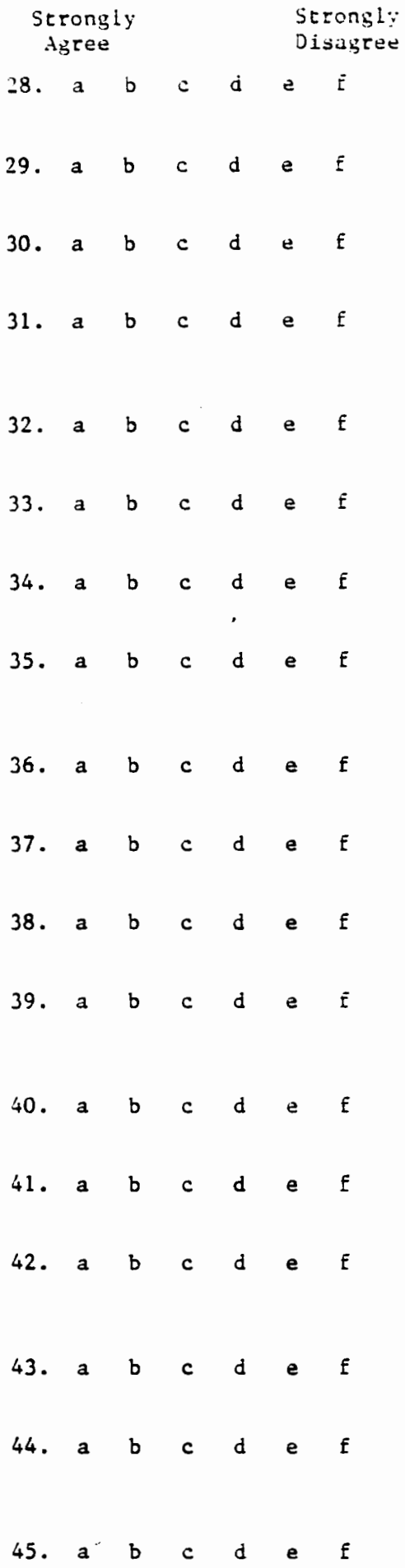


46. Psychiatric medication can help provide the energy to face overwhelming problems.

47. I would be hesitant to rake psychiatric medication prescribed for me without knowing all about it.

48. When I have emotional problems, I want psychiatric medicine prescribed for me.

49. Most prescribed psychlatric medicines are safe to take over a period of months.

50. I don't care how safe a psychiatric medication is reported to be, I still wouldn't take it.

51. I would not take medicine from a doctor who was disrespectful.

52. I think prescribed psychiatric medication can help patients concentrate better.

53. I take my medication regularly regardless of what my family thinks of it.

54. I belleve psychlacric medicines basically poison the body.

55. It is easy for me to neglect taking my medication when I get busy.

56. I would take psychiatric medicine prescribed for me and not worry about sclentific details.

57. Psychiatric medicine is only an emotional crutch.

58. Psychiatric medicines are too weak to help treat big problems.

59. If the doctor explains what effects the medicine ufight have on me, I would take it as prescribed.

60. I would take psychiatric medication I needed whether I liked the doctor or not.

61. I think it's always best to seek medical help for severe depression.

62. It would be impossible for me to take psychlatric medicine from a doctor I didn't trust.

63. I see psychlatric medicine as a last resort to coping with emotional problems.

64. You can't expect a patient to take psychiatric medication if no one cares.

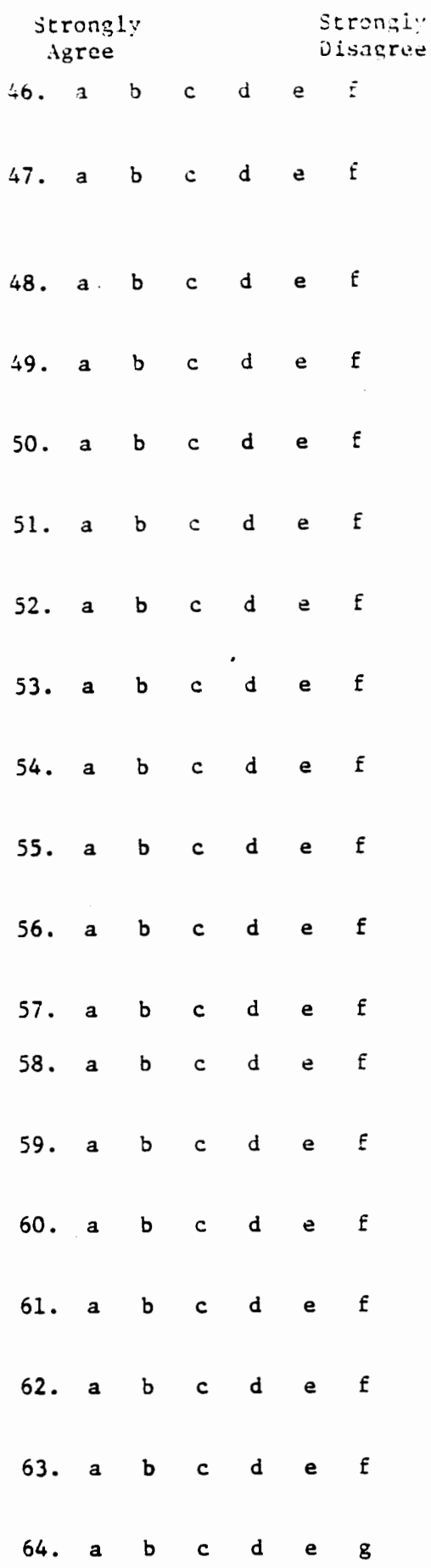


65. Psychiatric medicines which are prescribed by a doctor have been carefully screened by scientific studies.

66. Frequently, patients can learn new ways of coping because psychiatric medicines break up old anxiety patterns.

67. Even though psychtatric medicine might help with emotions; it usually makes it harder to think clearly.

68. I have no qualms about trying psychfatric medication my doctor recommends.

69. I think a patient should take prescribed psychiatric medicine even if farily and friends don't understand.

70. I think psychiatric medications almost always block you from having feelings you should experfence.

71. I think it is my duty to take psychiatric medication prescribed for me.

72. I'11 try whatever psychiatric medicine my doctor recoumends.

73. Once you begin taking psychiatric medicine, it is hard to give it up.

74. I believe prescribed psychiatric medicines usually would make a patient's thinking clearer because of less anxiety.

75. All the medical informacion in the world couldn't convince me to take psychiatric medication.

76. It would be easy for me to forget to take ny medication.

77. I belleve psychiatric medications can make it possible to learn new behavior in frightening situations.

78. The risk of sulcide is much greater than any risk in prescribed psychiatric medications.

79. Being more relaxed is something you can count on from taking psychiatric medicines.

80. Other people's opinions would never stop me from taking the medication I need.

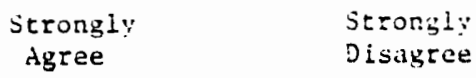

65. a b c d e t

66. a b c d e f

67. a b c d e

68. a b c d e E

69. a b c c d e e

70. $a$ b c $d \dot{d}$ e f

71. a b c $d$ e $f$

72. a b c d e f

73. a b c d e f

74. a b c d e

75. a b c d e f

76. a b c d e $\mathrm{f}$.

77. a b c c d e

78. a b c d e f

79. a b c d e f

80. a b c d e f 
APPENDIX D

PSYCHIATRIC MEDICINE ATTITUDE SCALE 
PSYCHIATRIC MEDICINE ATTITUDE SCALE A

NAME DATE

Age___ Sex___ Yeors of education completed____ Occupotion

Check all the statements that apply to you:

I hove never taken prescribed paychiotric medicine.

- I hove taken prescribed paychiatric medicine in the post.

- I am currently taking prescribed psychiatric medicine.

_ 1 am considering starting to take psychiatric medicine.

A person I know well (relative, friend) is currently taking or

has taken prescribed paychiatric medicine.

\section{INSTRUCTIONS}

Circle the letter which best corresponds to the way you feel about each statement.

\section{EXAMPLE}

1. The streets where I live are adequately poved.

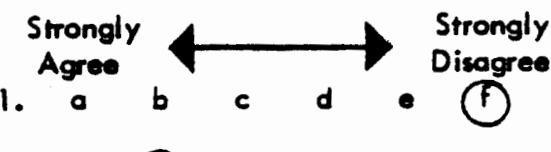

2. My neighbors are friendly.

2. 0

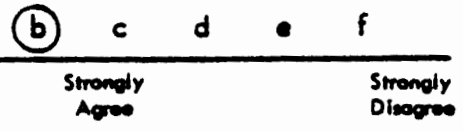

\section{QUESTIONNAIRE}

1. Poyehiowic medicine cen help provide the eneroy to face overwholming problems.

2. I think payehiotric medicines usally hove bed side effects.

3. I would take poyehletric medicetion preweribed for mo becoum I believe it is preity offective.

4. It is ean for me ro neglect taking my medteetion when I get bury.

5. I balieve prychiotic medicotion cen mote it powible to leam new behovior in frighrening sitwotions.

6. The rouble with paychiatric medicines is thot they just don't mork.

7. I would rake poychiatric modicin preseribed for me and not worry cbout seientific detoils.

8. Even cerefully preseribed poyehiatic madicines are much noo risky.

1. a b $c$ d $-f$

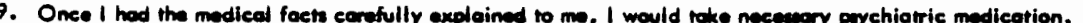

10. I don't believe in popehiowic medieines.

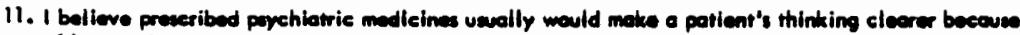
of lens enxiony.

2. a b c d

2. I would put up with wom uncomfortoble medicotion side effects in order to gat over a cerious depresesion. 12.

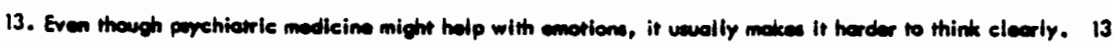

3. 0 b c d $\bullet$

4. a b c d $\bullet$

5. $a b a d b$

b. a b c d a

7. a b c d e

8. a b c d $\bullet$ t

9. a b c d $\bullet$

10. a b c d

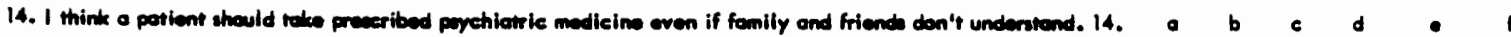

15. Onca you beain reking perpehlotric madleine, it is hard to give it up.

16. I hove no qualms about injing poyehiatsic medicention my decter reeconmends.

17. I would be relleved to find out that a cleas friend wo raking madicotion for dapresion.

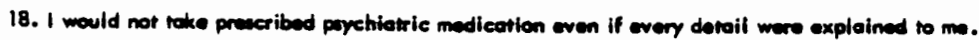

19. Whether you roke preseribed poychiotrie medieine exectly as directed just ien't very important.

20. I would rake preseribed poyshiotric madication for the sake of my loved onew.

15. a b c d $\bullet$ f

16. a b c d $\bullet$ f

17. a b c d $\bullet$

18. a b e d

19. 0 b c d e f

20. a b c d 
PSYCHIATRIC MEDICINE ATTITUDE SCALE

NAME DATE

Age Sox Years of education complated Occupation

Check all the statements that apply to you:

I hove never taken preseribod poychiatric medicine.

I I have taken prescribed poychiotric medicirie in the post. I am currently raking prescribed paychiatric medicine.

I an considering storting to take poychiatric medicine.

A person I know well (rolative, friend) is currently taking or has taken prescribed pychiatric medicine.

\section{INSTRUCTIONS}

Circle the letter which best corresponds to the way you feel about each statement.

\section{EXAMPLE}

1. The streets where I live ore odequately poved.

\section{Strongly Agree} I.
Strongly

Disagree

2. a

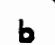

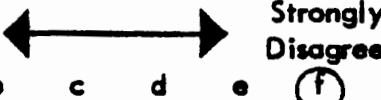

(b) $c d \bullet f$

2. My neighbors are friendly.

\section{QUESTIONNAIRE}

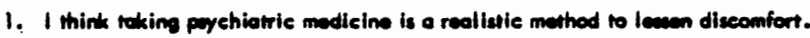

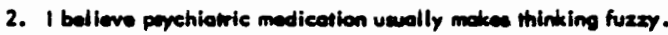

\begin{tabular}{|c|c|c|c|c|c|c|}
\hline \multicolumn{3}{|c|}{$\begin{array}{l}\text { Strondy } \\
\text { Agree }\end{array}$} & & & \multicolumn{2}{|c|}{$\begin{array}{l}\text { Strongly } \\
\text { Disegres }\end{array}$} \\
\hline 1. & - & b & c & d & • & $f$ \\
\hline 2. & a & b & c & d. & - & f \\
\hline 3. & a & b & c & d & $\bullet$ & 1 \\
\hline 4. & - & b & c & d & $\bullet$ & $f$ \\
\hline 5. & $a$ & b & c & d & - & f \\
\hline 6. & a & b & c & $d$ & - & $f$ \\
\hline 7. & $a$ & b & c & $d$ & - & f \\
\hline 8. & - & b & c & d & • & $f$ \\
\hline 9. & - & b & c & d & - & $f$ \\
\hline 10. & a & b & c & $d$ & • & $f$ \\
\hline 11. & a & b & $c$ & d & $\bullet$ & $f$ \\
\hline 12. & a & b & c & d & $\bullet$ & $f$ \\
\hline 13. & $a$ & b & e & d & $\bullet$ & $f$ \\
\hline 14. & $a$ & b & e & d & • & $f$ \\
\hline 15. & - & b & c & d & $\bullet$ & f \\
\hline 16. & - & b & e & d & $\bullet$ & $f$ \\
\hline 17. & a & b & e & $d$ & $\bullet$ & $f$ \\
\hline 18. & - & b & $c$ & d & $\bullet$ & $f$ \\
\hline 19. & - & b & c & $d$ & $\bullet$ & $f$ \\
\hline 20. & a & b & $c$ & $d$ & $\bullet$ & $f$ \\
\hline
\end{tabular}

3. Hoving the seientifle informotion would influence mo to teke popehiotrie medieotion preceribed.for me.

4. Poychiotic medicina unedly cover up problems that should be foead.

5. I'll try whatever payehlotric medicine my docter recantands.

6. I don't cors how sofe a parehiotric medicotion is reparted to be, I still wouldn't take it.

7. One of the beet thing about most poychiotric modication is thet there is no risk of addiction.

8. All the medical information in the world couldn't cominee me to roke poyehiotric medication.

9. If the doeter exploin whot effects the medicine might hove on me, I would reke it as preacribed.

10. I think paychiotrie medieation dimest alwors block you from hevino feeling you should experieneo.

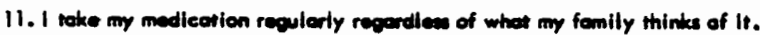

12. I would rother hove paychologieet ecuneding forever then toke poyshiotris medieines.

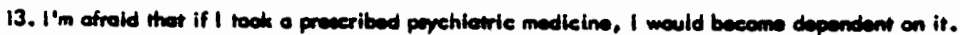

14. Pryehiotric medicine might give me the eneror to think eleady if I were dopresed.

15. Pypchiotric modicotions are hebit-forming.

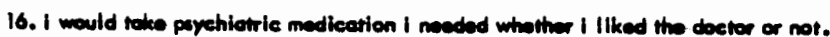

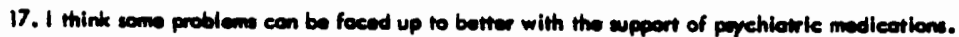

18. Frequently, petienrs cen feorn now woys of ceping beceuve prychiotric medicines breck up old anxiony potterns.

19. 1 would bo hasitust to teke pychiortic medicetion preseribed for me without knowing all about it.

20. I thist preceribed poychietric medicotion cen help potients concentrote better. 